\title{
Understanding model diversity in future precipitation projections for South America
}

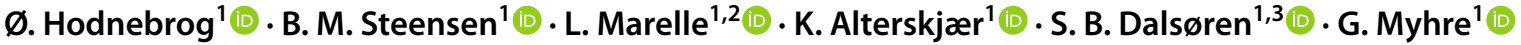

Received: 22 December 2020 / Accepted: 9 September 2021 / Published online: 22 September 2021

(c) The Author(s) 2021

\begin{abstract}
Precipitation patterns are expected to change in the future climate, affecting humans through a number of factors. Global climate models (GCM) are our best tools for projecting large-scale changes in climate, but they cannot make reliable projections locally. To abate this problem, we have downscaled three GCMs with the Weather Research and Forecasting (WRF) model to $50 \mathrm{~km}$ horizontal resolution over South America, and $10 \mathrm{~km}$ resolution for central Chile, Peru and southern Brazil. Historical simulations for years 1996-2005 generally compare well to precipitation observations and reanalyses. Future simulations for central Chile show reductions in annual precipitation and increases in the number of dry days at the end-of-the-century for a high greenhouse gas emission scenario, regardless of resolution and GCM boundary conditions used. However, future projections for Peru and southern Brazil are more uncertain, and simulations show that increasing the model resolution can switch the sign of precipitation projections. Differences in future precipitation changes between global/regional and high resolution $(10 \mathrm{~km})$ are only mildly influenced by the orography resolution, but linked to the convection parameterization, reflected in very different changes in dry static energy flux divergence, vertical velocity and boundary layer height. Our findings imply that using results directly from GCMs, and even from coarse-resolution $(50 \mathrm{~km})$ regional models, may give incorrect conclusions about regional-scale precipitation projections. While climate modelling at convection-permitting scales is computationally costly, we show that coarse-resolution regional simulations using a scale-aware convection parameterization, instead of a more conventional scheme, better mirror fine-resolution precipitation projections.
\end{abstract}

Keywords Regional climate modelling · Precipitation projections · Extremes · South America · Weather Research and Forecasting (WRF)

\section{Introduction}

Changes in precipitation patterns can affect human society in many ways, e.g. through freshwater availability, crop yields and hydropower production. While global and annual mean precipitation increases at $1-3 \%$ per degree kelvin of global warming (Boucher et al. 2013; Held and Soden 2006), changes are far from homogeneously distributed spatially or seasonally (Collins et al. 2013). While global climate models

Ø. Hodnebrog

oivind.hodnebrog@cicero.oslo.no

1 CICERO Center for International Climate Research, Oslo, Norway

2 Present Address: LATMOS/IPSL, Sorbonne Université, UVSQ, CNRS, Paris, France

3 Present Address: Institute of Marine Research, Bergen, Norway
(GCMs) are our best tools for projecting large-scale changes in precipitation, they have too coarse horizontal resolution (typically $1-2^{\circ}$ ) to project changes at the regional scale. Regional climate models (RCMs) were therefore developed to resolve the inhomogeneous responses of climate change (Giorgi 2019).

There has been a scarcity of regional climate change studies for South America, partly due to lack of available high quality and continuous climate and hydrological data at high resolution (Magrin et al. 2014). However, several recent and ongoing initiatives, such as through the framework of the Coordinated Regional Climate Downscaling Experiment (CORDEX) (Giorgi and Gutowski 2015; Gutowski et al. 2016) and the Europe-South America Network for Climate Change Assessment and Impact Studies (CLARIS) (Boulanger et al. 2010), have led to an increase in the number of publications devoted to regional climate modelling studies over South America in recent years (Ambrizzi et al. 2019; 
Solman 2013). Still, there are few studies with high horizontal resolution $(<40 \mathrm{~km})$ covering long (climatological) time horizons (Ambrizzi et al. 2019).

Llopart et al. (2020) found that CORDEX RCMs simulated more realistic precipitation fields in several regions in South America compared to their driving GCMs. Assuming a high greenhouse gas emission scenario, the Representative Concentration Pathway (RCP) 8.5 (van Vuuren et al. 2011), they found large differences between regions and seasons in projected precipitation for the end of the twentyfirst century, ranging from $+14 \%$ over northeastern Brazil in austral summer to $-36 \%$ over the Andes Mountains in winter. Results from other RCM studies are summarized in the review articles by Ambrizzi et al. (2019) and Solman (2013).

Several studies have documented added value of increased model resolution in reproducing historical precipitation (e.g. Bozkurt et al. 2019; da Silva et al. 2019; PosadaMarin et al. 2019; Solman and Blazquez 2019). However, the influence of high model resolution for the magnitude and sign of future precipitation change has received less attention. Llopart et al. (2020) show, at least in terms of water resources (precipitation minus evapotranspiration), that the future trends in annual cycles have different signs in the GCMs and RCMs in some regions (e.g. the Andes), indicating that the choice of model resolution is important for the calculated precipitation trend. Bozkurt et al. (2021) found that GCMs and RCMs can give notable differences in projected precipitation patterns and magnitudes over the Antarctic Peninsula. Kendon et al. (2017) focused on the midlatitudes and concluded that there was little difference in seasonal mean precipitation projections between coarser to higher RCM resolution.

High model resolution could be particularly important for South America; its climate is characterized by the long meridional extent of the continent, from around $55^{\circ} \mathrm{S}$ to $10^{\circ} \mathrm{N}$, leading to tropical, subtropical and extratropical features. In addition, the climate is strongly influenced by the complex orography of the Andes Mountains, which extend along the western edge of South America and act as a climatic wall (Garreaud et al. 2009; Solman 2013), and by the Amazon rainforest, which is a large source of moisture. The large-scale phenomenom El Niño Southern Oscillation (ENSO) adds complexity and leads to a strong interannual variability in the region. The Madden-Julian Oscillation (MJO) influences South American climate (Alvarez et al. 2016; Julia et al. 2012), and Atlantic air-sea interactions have been deemed important for the MJO influence on precipitation in eastern South America (Barreiro et al. 2019). Three sub-regions of South America have been selected for high resolution $(10 \mathrm{~km})$ modelling, each with different climatic features largely shaped by aforementioned large-scale patterns and local-scale orography.
A main aim of this study is to investigate future precipitation changes in selected regions in South America at higher model resolution than what has commonly been used before. By downscaling three different GCM realizations, we also assess the influence of lateral boundary conditions on the downscaled precipitation projections. To increase our understanding of precipitation changes we include energy budget analysis and sensitivity experiments. Analysis of the Earth's energy budget has proved useful in understanding responses of precipitation to climate change, both globally (e.g. Allen and Ingram 2002; Muller and O'Gorman 2011; Myhre et al. 2018; Pendergrass and Hartmann 2014; Previdi 2010; Richardson et al. 2018a) and regionally (e.g. Hodnebrog et al. 2016; Richardson et al. 2018b). We also provide an analysis of potential future changes in daily extreme precipitation, which historically has shown to impact large areas of South America, e.g., in terms of damage to agriculture, water resources, and economic losses (Avila et al. 2016; Cavalcanti et al. 2015; Gonzalez et al. 2019; Tencer et al. 2016).

Section 2 gives brief descriptions of the three selected study regions and documents the observations, models and experimental setup. In Sect. 3, we present our results and compare them to observations. The results are further discussed and compared to previous findings in Sect. 4, and summarized in Sect. 5.

\section{Methods}

\subsection{Study regions}

This study focuses on high resolution modelling for three sub-regions of South America: central Chile, Peru and southern Brazil (Fig. 1). The three regions have been chosen because they are among the most populated regions in South America, they encompass several hydropower plants, and they represent different climates. Two of the regions, central Chile and Peru, are also exposed to potential climate change induced snow cover reductions and glacier retreats, which influence water availability (Bozkurt et al. 2018; Masiokas et al. 2006; Vuille et al. 2018).

For the Chilean and Peruvian climate, the narrow land region between the coastline and the Andes from $\sim 30^{\circ} \mathrm{S}$ to $5^{\circ} \mathrm{S}$ is characterized by extreme aridity (e.g., Garreaud et al. 2009). The east side of the Andes in Peru, however, is influenced by transport of humid air from the Atlantic Ocean and Amazonas region in the east, especially during austral summer when the Intertropical Convergence Zone (ITCZ) is located south of the Equator, and is therefore characterized by relatively large precipitation amounts and a relatively strong seasonal precipitation cycle (e.g., Segura et al. 2019). Low-level jets at both sides of the Andes can transport large 

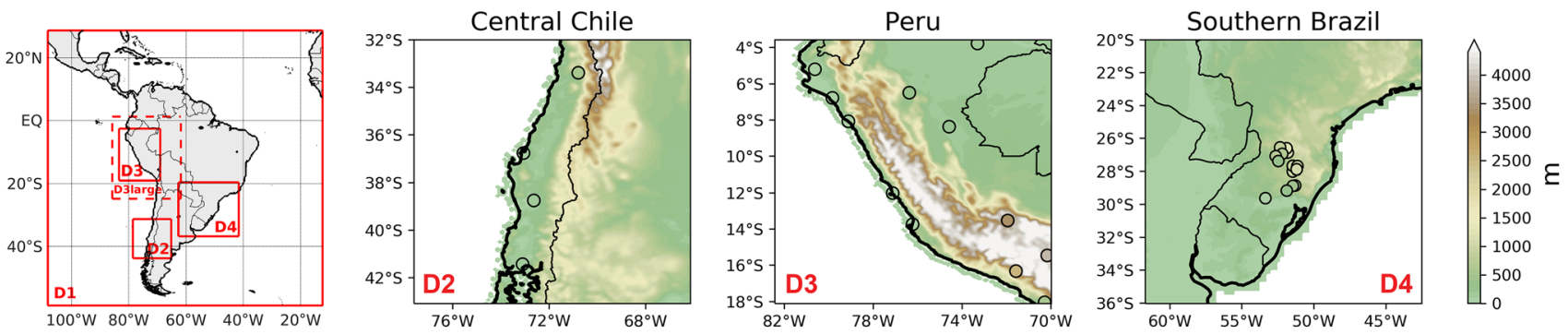

Fig. 1 Overview of domains used in the WRF model. Location and extent of each domain (1st column) and elevation (m) in the high resolution domains and the GHCN-Daily/Hidroweb stations (colored circles) (2nd-4th column). D1 has a horizontal resolution of $50 \mathrm{~km}$ and D2-D4 have $10 \mathrm{~km}$ resolution. The domains cover South America (D1), central Chile (D2), Peru (D3 and D3large) and southern Brazil (D4)

(Schneider et al. 2018). The GPCC product includes monthly land-surface precipitation based on $\sim 80,000$ raingauge stations across the globe and covers the time period 1891-2016. For central Chile and Peru, individual station observations have been taken from version 3.22 of the Global Historical Climatology Network-Daily (GHCNDaily) (Menne et al. 2012), which contains daily climate records from over 100,000 land-based stations world wide in the timespan between 1832 and present-day. For southern Brazil, individual station observations have been taken from Hidroweb from the Brazilian National Water Agency (ANA) (Hidroweb 2017).

\subsection{Regional WRF model}

The Weather Research and Forecasting (WRF) model (Skamarock and Klemp 2008) version 3.8.1 has been used at a horizontal resolution of $50 \mathrm{~km} \times 50 \mathrm{~km}$ covering all of South America. One-way nesting was applied from the $50 \mathrm{~km} \times 50 \mathrm{~km}$ domain to a resolution of $10 \mathrm{~km} \times 10 \mathrm{~km}$ resolution over selected subregions (Fig. 1; Supplementary Table S1). An outer boundary of 10 grid boxes in each domain was ignored for the analysis. The number of vertical layers in all domains was 35 , extending from the surface and up to $50 \mathrm{hPa}$. Choices of physics schemes are given in Supplementary Table $\mathrm{S} 2$.

Table 1 gives an overview of the different experiments and the meteorological initial and boundary conditions used Climatology Centre (GPCC) (Becker et al. 2013) version 2018 have been used at a spatial resolution of $0.25^{\circ} \times 0.25^{\circ}$

\begin{tabular}{llll}
\hline Acronym & Global model or reanalysis & Historical period & Future periods \\
\hline WRF_NNRP & NCEP/NCAR reanalysis (Kalnay et al. 1996) & $1986-2005$ & \\
WRF_CESM & CESM1-CAM4 (Hodnebrog et al. 2019) & $1986-2005$ & 2041-2060 RCP4.5; \\
& & & 2081-2100 RCP8.5 \\
WRF_CCSM4 & CCSM4 (CMIP5: Taylor et al. 2011) & $1996-2005$ & 2091-2100 RCP8.5 \\
WRF_ACC & ACCESS1-0 (CMIP5: Taylor et al. 2011) & $1996-2005$ & 2091-2100 RCP8.5 \\
\hline
\end{tabular}


(see Sect. 2.4 for description of GCM data used). Boundary conditions were updated in WRF every $6 \mathrm{~h}$ and spectral nudging to the global data was applied for temperature, horizontal winds and geopotential height in the outermost $(50 \mathrm{~km})$ domain. We used a spectral nudging coefficient of $0.0003 \mathrm{~s}^{-1}$ and $\mathrm{x} / \mathrm{y}$ wave numbers of 6/6, 6/8, 12/17 and 9/13 for WRF_NNRP, WRF_CESM, WRF_CCSM4 and WRF_ACC, respectively. Sea-surface temperatures were also from the global reanalysis or climate model data and updated daily in WRF. For the southern Brazil domain, the WRF_NNRP and WRF_CESM simulations used a slightly different WRF version (3.7.1) and a resolution of $12 \mathrm{~km}$ (Supplementary Fig. 1; Supplementary Table S1), but for the analysis the $12 \mathrm{~km}$ results were regridded to the $10 \mathrm{~km}$ domain grid (D4 in Fig. 1). Another difference in the setup is that the simulations with initial and boundary conditions from the CMIP5 models (WRF_CCSM4 and WRF_ACC) are continuous runs with one year of spin-up starting from 1st of Jan. 1995 for the historical simulation and 1st of Jan. 2090 for the future simulation, while the other simulations (WRF_NNRP and WRF_CESM) have been run in 13-month time slices re-initialized at $1^{\text {st }}$ of Dec. each year and with the first month disregarded as spin-up. While one month of spin-up should be sufficient for the atmosphere, it means that soil temperature and moisture are more dependent on the initial conditions (coming from the reanalysis or GCM) in the time slice simulations than in the continuous simulations. However, any trends in the data should be captured through the initial conditions, and an earlier study found only small differences in precipitation change when using 1 vs. 8 months of spin-up (Hodnebrog et al. 2019).

To ensure a good signal-to-noise ratio in the future climate simulations, we have used GCM boundary conditions assuming the high emission pathway RCP8.5, but performed additional simulations with WRF_CESM using the more moderate emission pathway RCP4.5 (van Vuuren et al. 2011). Other than changing the meteorological initial and boundary conditions and the greenhouse gas volume mixing ratios in the WRF radiation schemes, no other changes, such as aerosol concentration changes and land cover changes, were made in the WRF simulations for the future time periods.

Table 2 describes four additional WRF sensitivity simulations that have been carried out for Peru only, to investigate potential reasons to why precipitation projections in this region differ depending on model resolution (see Sect. 3.2.3 for further details). These simulations use CCSM4 as initial and boundary conditions and, due to computational constraints, are shorter than the main simulations, with three years (plus 1 year spin-up) for each of the historical and future time periods.

\subsection{Global climate models}

The GCMs listed in Table 1 have both been used as boundary conditions to the WRF model and been analysed directly for comparison to the regional model results. Data for two of the global climate models, CCSM4 and ACCESS1-0, have been downloaded from the Coupled Model Intercomparison Project phase 5 (CMIP5) archive (Taylor et al. 2011) for the experiments "historical" and "rcp85". Ensemble member "r6i1p1" was used for CCSM4 and "r1ilp1" for ACCESS1-0. The third global climate model, the National Center for Atmospheric Research (NCAR) Community Earth System Model (CESM1-CAM4) (Gent et al. 2011), is essentially the same model as CCSM4, but it is run in-house and the setup is documented in Hodnebrog et al. (2019). To some extent, the CCSM4 and CESM model simulations can be considered two different realizations of the same model. The main difference in the setup between the CCSM4 and CESM simulations is the horizontal resolution, which is $1.25^{\circ} \times 0.94^{\circ}$ (lon x lat) and $2.5^{\circ} \times 1.88^{\circ}$, respectively. ACCESS1-0 has a horizontal resolution of $1.88^{\circ} \times 1.24^{\circ}$. To convert from the GCMs' output in NetCDF format to the GRIB format needed by the WRF pre-processor, we have modified and used the cam_to_wps utility available at https://github.com/shortwavetrough/cam_to_wps.

In the Results section we also compare with an ensemble mean of 18 different CMIP5 models, and these are ACCESS1-3, bcc-csm1-1-m, BNU-ESM, CanESM2,

Table 2 Sensitivity simulations with WRF for Peru

\begin{tabular}{|c|c|c|c|}
\hline Acronym & Description & Historical period & Future period \\
\hline WRF_CCSM4_topo & $\begin{array}{l}\text { Same as WRF_CCSM4 but with the terrain height in the } 10 \mathrm{~km} \text { domain } \\
\text { smoothed to equal the } 50 \mathrm{~km} \text { resolution in the outermost domain }\end{array}$ & 1996-1998 & 2091-2093 RCP8.5 \\
\hline WRF_CCSM4_large & $\begin{array}{l}\text { Same as WRF_CCSM4 but with increased size of the } 10 \mathrm{~km} \text { domain, from } \\
150 \times 175 \text { to } 250 \times 280 \text { grid boxes (D3 vs. D3large in Fig. } 1 \text { ) }\end{array}$ & 1996-1998 & 2091-2093 RCP8.5 \\
\hline WRF_CCSM4_noCP & $\begin{array}{l}\text { Same as WRF_CCSM4 but with cumulus parameterization turned off in } 10 \mathrm{~km} \\
\text { domain }\end{array}$ & 1996-1998 & 2091-2093 RCP8.5 \\
\hline WRF_CCSM4_cpGF & $\begin{array}{l}\text { Same as WRF_CCSM4 but with cumulus parameterization changed from } \\
\text { Kain-Fritsch scheme (Kain 2004) to Grell-Freitas ensemble scheme (Grell and } \\
\text { Freitas 2014) }\end{array}$ & 1996-1998 & 2091-2093 RCP8.5 \\
\hline
\end{tabular}


CCSM4, CESM1-CAM5, CMCC-CMS, CNRM-CM5, CSIRO-Mk3-6-0, FGOALS-g2, GFDL-CM3, GISS-E2-R, HadGEM2-ES, inmcm4, MIROC-ESM, MPI-ESM-LR, MRI-CGCM3 and NorESM1-M. We also compare with 16 different CMIP6 models (Eyring et al. 2016) for the experiments "historical" and "ssp585": ACCESS-CM2, ACCESSESM1-5, CESM2, CNRM-CM6-1, CNRM-ESM2-1, EC-Earth3, EC-Earth3-Veg, FGOALS-g3, INM-CM5-0, IPSL-CM6A-LR, MIROC6, MPI-ESM1-2, MRI-ESM2-0, NESM3, NorESM2-MM and UKESM1-0-LL. The CMIP5 and CMIP6 data were all for ensemble member "r1i1p1" and regridded to $1^{\circ} \times 1^{\circ}$ resolution for the analysis.

\subsection{Reanalysis datasets}

In addition to the WRF simulations using boundary conditions from GCMs, reanalysis data have been downscaled using boundary conditions from the National Centers for Environmental Prediction (NCEP) / NCAR Reanalysis Project (NNRP) (Kalnay et al. 1996) in the simulation named WRF_NNRP (Table 1). For comparison with GPCC and the WRF simulations, we have also analysed a different dataset, ERA5-Land (Muñoz-Sabater 2020), which is based on the $5^{\text {th }}$ generation reanalysis from the European Centre for Medium-Range Weather Forecasts (ECMWF), ERA5. ERA5-Land is a replay of the land component in ERA5 at a finer spatial resolution of approximately $9 \mathrm{~km} \times 9 \mathrm{~km}$ (regridded to $0.1^{\circ} \times 0.1^{\circ}$ ), compared to $30 \mathrm{~km} \times 30 \mathrm{~km}$ in ERA5.

\subsection{Atmospheric energy budget analysis}

Precipitation is constrained by the atmospheric energy balance (Allen and Ingram 2002). The regional atmospheric energy budget can be used to better understand how precipitation responds to a perturbation in climate (denoted $\delta$ ) and can be written (e.g. as in Richardson et al. 2018b)

$L \delta P=\delta L W+\delta S W-\delta S H+\delta H_{d r y}=\delta L H+L \delta M$

where $L$ is the latent heat of condensation, $P$ is the surface precipitation flux, LW and SW are the atmospheric longwave and shortwave radiative cooling, respectively, SH is the sensible heat flux from the surface, $H_{\mathrm{dry}}$ is the dry static energy flux divergence, $\mathrm{LH}$ is the latent heat flux from the surface and $M$ is moisture convergence. $\delta H_{\text {dry }}$ and $\delta M$ are not calculated explicitly in the model but taken as residuals in the analysis. The global atmospheric energy budget is represented by the same equation except that $\delta H_{\text {dry }}$ and $\delta M$ would be zero. Changes in horizontal and vertical winds drive $H_{\text {dry }}$, while $M$ is equivalent to precipitation minus evapotranspiration $(P-E)$.

\section{Results}

\subsection{Model evaluation}

\subsubsection{Annual precipitation distribution}

Figure 2 shows that the WRF model simulations and ERA5-Land broadly reproduce the main features of the South American precipitation, as represented by the GPCC precipitation observations; a peak in annual precipitation in the north, dry conditions in the west, and another but weaker precipitation peak in the southwest. These features are also reproduced by the GCMs used as boundary conditions to WRF (Supplementary Fig. S2). However, there is too much precipitation over the northern parts of South America in WRF compared to both GPCC and ERA5-Land, and this is more prominent in the WRF_ACC simulation. Further investigation indicates that this is due to more moisture transport from the Atlantic in the east in WRF_ACC compared to the two other simulations, and this is particularly evident during austral winter (not shown).

In central Chile, WRF and ERA5-Land compare very well to the GHCN-Daily precipitation observations (Fig. 2), but WRF has more precipitation in the mountainous eastern part of Chile compared to the GPCC observations (see Fig. 1 for elevation map). However, GPCC precipitation is based on spatial interpolation from station observations, and very few stations are available in this area. Thus it is difficult to know the actual precipitation amounts, but the precipitation pattern in the WRF simulations agree relatively well with the ERA5-Land reanalysis (Fig. 2). Lack of high-quality surface precipitation observations in the Andes has also been mentioned previously (Alvarez-Garreton et al. 2018; Bozkurt et al. 2019).

In Peru, the very dry conditions near the coast are seen in all datasets; GPCC, GHCN-Daily, ERA5-Land and all WRF simulations (both forced with reanalysis and with free-running GCMs). Further from the coast, GPCC and WRF disagree, and the few GHCN-Daily stations that exist indicate that WRF has too much precipitation in the eastern part of Peru, in particular in WRF_CCSM4 and WRF_CESM. In the southeast of Peru, overestimation of precipitation is also seen in the GCMs used as boundary conditions to WRF (Supplementary Fig. S2).

In southern Brazil, GPCC shows a peak in annual precipitation in the center of the domain (Fig. 2). The precipitation pattern in GPCC is similar in ERA5-Land, and also reasonably well reproduced in the WRF simulations, except for very low precipitation amounts in the western part of the domain in WRF_ACC. 

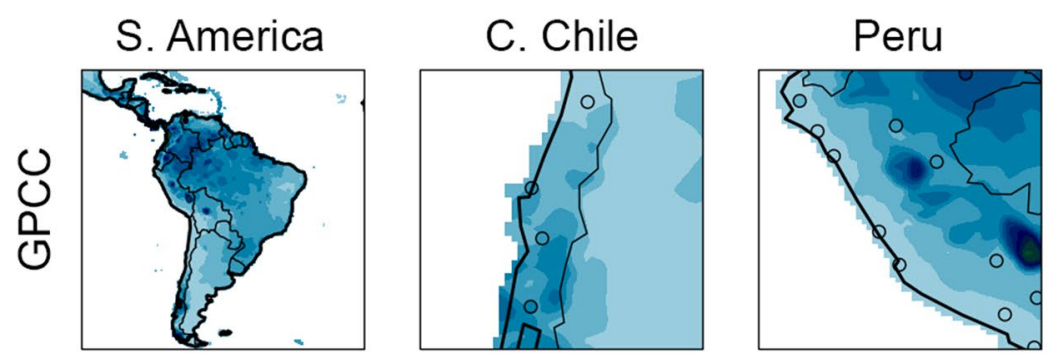

S. Brazil
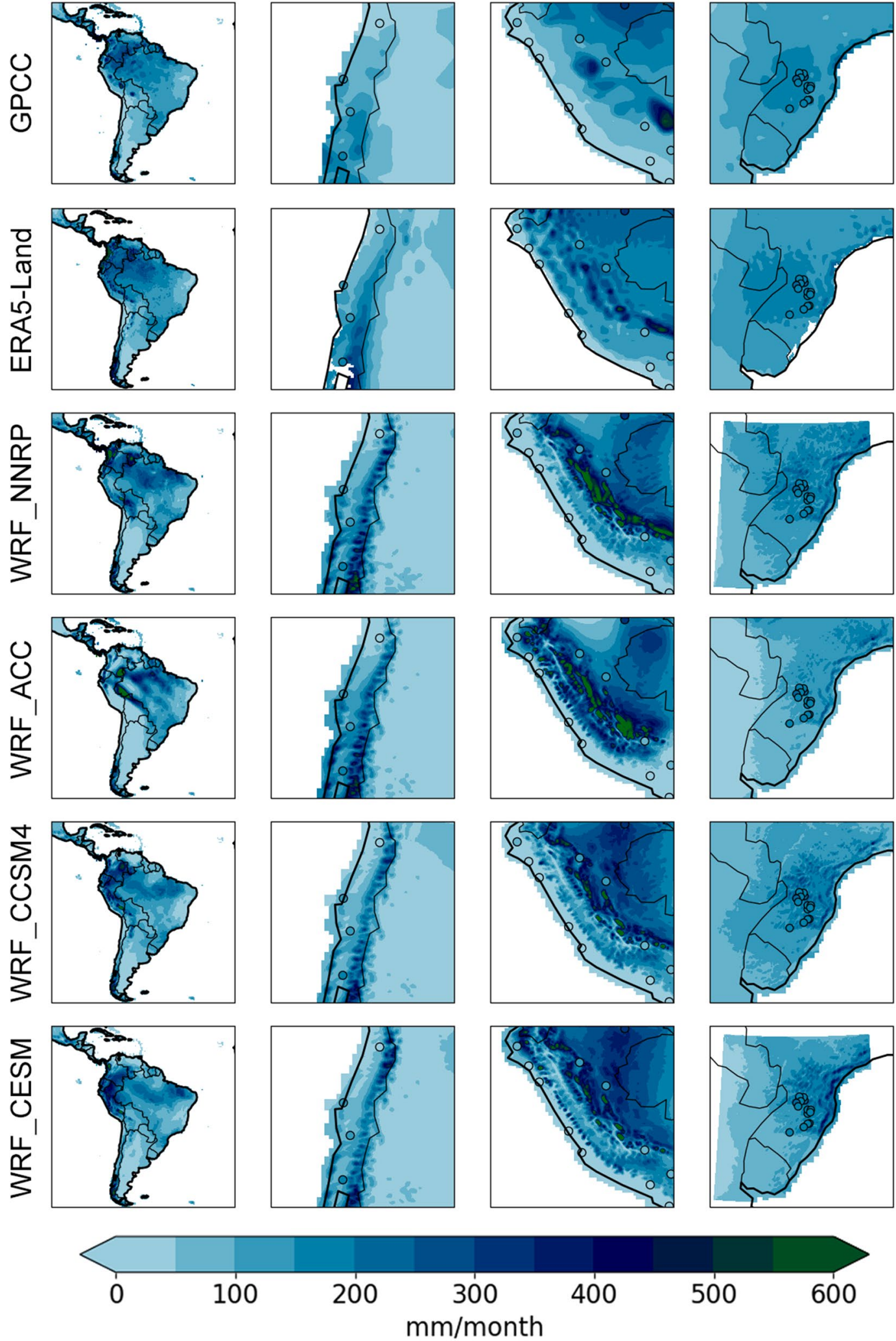

Fig. 2 Annual mean precipitation (mm month ${ }^{-1}$ ) over land in GPCC observations (1st row), ERA5-Land reanalysis (2nd row) and WRF simulations (3rd-6th row). Colored circles are GHCN-Daily/Hidroweb station observations 


\subsubsection{Seasonal precipitation cycle}

Figure $3 \mathrm{a}$ and Table 3 show that the spatially averaged seasonal precipitation cycle is very well reproduced for all regions by WRF when driven by the NNRP reanalysis data, both in terms of monthly amounts and the temporal distribution. Interestingly, for the central Chile and Peru regions there is better agreement with the GPCC observations for the WRF_NNRP run at $50 \mathrm{~km}$ (yellow dashed lines) than at $10 \mathrm{~km}$ (yellow solid lines). However, the higher precipitation amounts in the $10 \mathrm{~km}$ run compared with the $50 \mathrm{~km}$ run, during austral winter in central Chile and austral summer in Peru, are in mountainous regions where rain gauge station observations are sparse (Figs. 1, 2). This may indicate that GPCC, which is purely based on rain gauge stations and no modelling or satellite products, does not account for these high precipitation amounts in, and close to, the Andes Mountains. It is, however, reassuring that the $10 \mathrm{~km}$ resolution WRF results compare relatively well to the ERA5-Land reanalysis (Fig. 3a). For central Chile, Bozkurt et al. (2019) performed a comparison of runoff-precipitation covariability using observations of discharge, and found indications of precipitation underestimation in gridded observational datasets.
Table 3 Correlation coefficient between seasonal land-only precipitation cycle in GPCC observations vs. ERA5-Land, GCMs and WRF simulations

\begin{tabular}{lllll}
\hline & S. America & C. Chile & Peru & S. Brazil \\
\hline ERA5-Land & 0.99 & 0.98 & 0.99 & 0.98 \\
ACCESS1-0 & 0.93 & 0.92 & 0.96 & 0.97 \\
WRF ACC 50 km & 0.92 & 0.90 & 0.95 & 0.92 \\
WRF ACC 10 km & & 0.91 & 0.89 & 0.89 \\
CCSM4 & 0.92 & 0.60 & 0.94 & 0.96 \\
WRF CCSM4 50 km & 0.95 & 0.84 & 0.89 & 0.94 \\
WRF CCSM4 10 km & & 0.88 & 0.93 & 0.91 \\
CESM & 0.87 & 0.53 & 0.86 & 0.92 \\
WRF CESM 50 km & 0.92 & 0.91 & 0.86 & 0.90 \\
WRF CESM 10 km & & 0.93 & 0.92 & 0.90 \\
WRF NNRP 50 km & 0.97 & 0.98 & 0.96 & 0.99 \\
WRF NNRP 10 km & & 0.99 & 0.91 & 0.97 \\
\hline
\end{tabular}

Comparison with individual GHCN-Daily station observations shows very good agreement for WRF_NNRP for central Chile, with slightly better performance for the $10 \mathrm{~km}$ run compared to the $50 \mathrm{~km}$ run (Supplementary Fig. S3). For Peru, WRF_NNRP at $10 \mathrm{~km}$ resolution performs better than $50 \mathrm{~km}$ resolution for the high altitude stations while
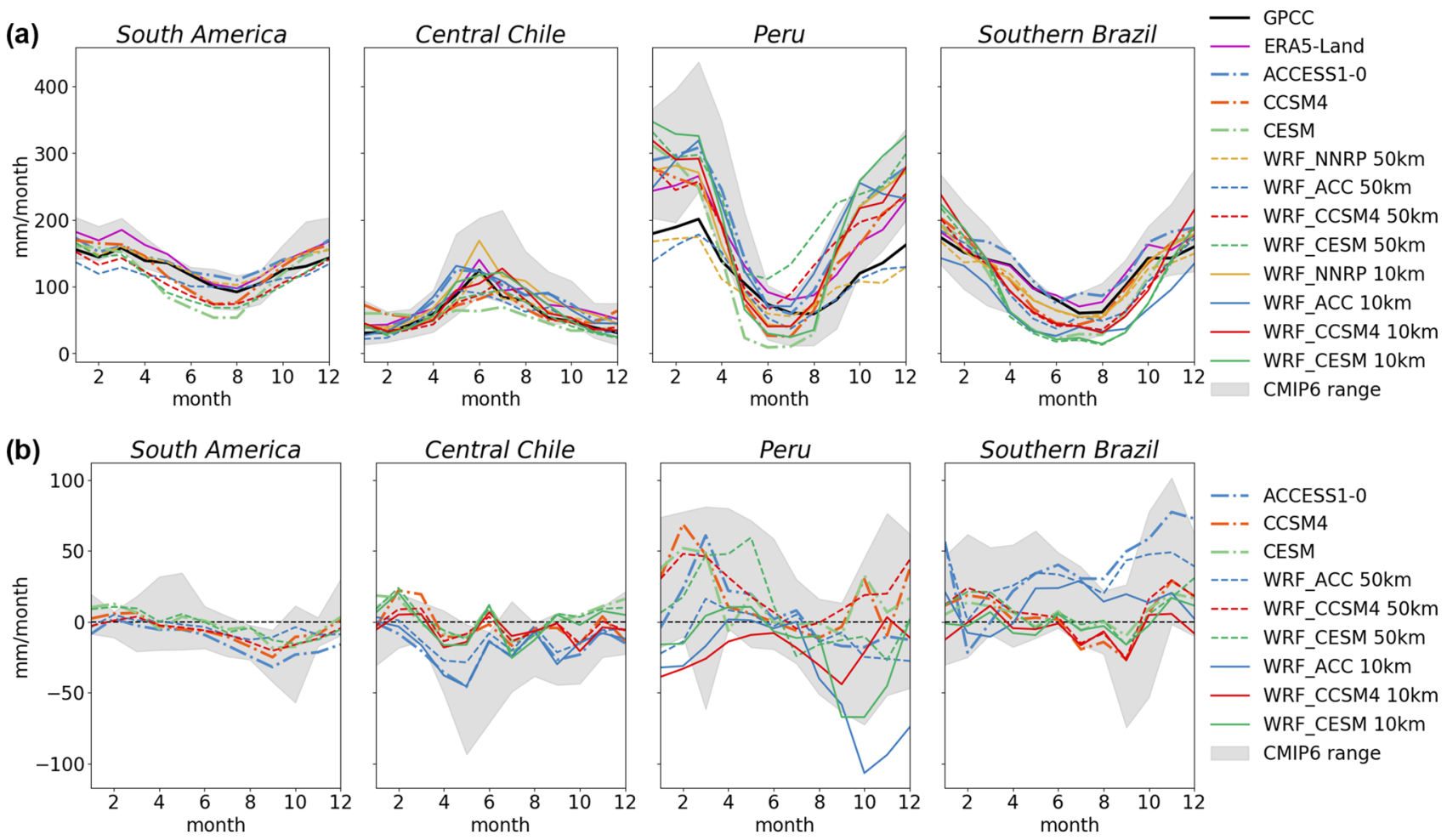

Fig. 3 a Historical 10-year average (1996-2005) monthly precipitation cycle $\left(\mathrm{mm} \mathrm{month}{ }^{-1}\right)$ in GPCC observations, ERA5-Land, GCMs and WRF for different regions, and $\mathbf{b}$ future changes (1996-2005 vs.

2091-2100RCP8.5) projected by GCMs and WRF. Landmasks have been used to only consider land gridpoints for the regional averaging 
the $10 \mathrm{~km}$ resolution run seems to overestimate precipitation amounts at some of the low altitude stations with low observed precipitation amounts. In southern Brazil, both the monthly amounts and the temporal distribution of the observed seasonal precipitation cycle at individual Hidroweb stations are well reproduced by the WRF_NNRP simulation, and there are no large differences between results from the $10 \mathrm{~km}$ and $50 \mathrm{~km}$ resolution runs.

WRF simulations using boundary conditions from a reanalysis dataset, as in WRF_NNRP, are expected to perform better than WRF simulations using boundary conditions from free-running GCMs, because reanalyses include assimilation of actual observations. Comparison to GPCC indicates that the seasonal precipitation cycle is exaggerated for Peru and southern Brazil when using GCMs as boundary conditions, particularly for WRF_CESM and WRF_CCSM4, with too low values during austral winter and too high values during austral summer (Fig. 3a). Again, this may partly be due to lack of observations in the Peruvian mountain regions. Comparison to individual station observations shows a similar tendency of an exaggerated seasonal cycle at some stations in both Peru and southern Brazil (Supplementary Fig. S3), but it should be noted that the comparisons against observations are made for a historical period of 10 years (1996-2005) and therefore expected to be influenced by natural variability (only the WRF_NNRP simulation, and not the simulations based on free-running GCMs, can be expected to reproduce the meteorology during this exact period). It may also be that an even higher model resolution than $10 \mathrm{~km}$ is needed to better resolve the highly complex terrain and climate zones in Peru. Improved representation of fine-scale orography and variations of surface fields can be especially beneficial in mountainous regions, partly because surface heterogeneity is an important driver for deep convection (Prein et al. 2015, and references therein). It has also been shown that even $3 \mathrm{~km}$ resolution is insufficient to reproduce precipitation amounts at individual stations in a region of complex terrain (Hodnebrog et al. 2019). For Chile, there are relatively small biases against GHCN-Daily in the $10 \mathrm{~km}$ WRF runs and the correlation coefficient is above 0.70 for all stations.

\subsection{Projected precipitation changes}

\subsubsection{Future changes in the annual precipitation distribution}

Figure 4a shows that the three GCM simulations broadly agree on a future decrease in precipitation in the northeast and southwest of South America and on an increase in the west and southeast. These patterns are also similar to those projected by the ensemble mean of 18 CMIP5 and 16 CMIP6 GCMs. As expected, the CCSM4 and CESM model simulations, which are based on a very similar setup and model version, show more similarities to each other than ACCESS1-0 to either of CCSM4 or CESM. The three GCM simulations show the least agreement in the sign of the precipitation change in the northwest of South America and in parts of Brazil. In most of South America, patterns of precipitation change are relatively similar between the WRF $50 \mathrm{~km}$ simulations and their driving GCM, but the magnitude of the relative precipitation change often differ more (e.g. ACCESS1-0 vs. WRF_ACC in northern Argentina). Inter-model differences in precipitation pattern changes could be linked to potential changes in circulations patterns at synoptic scales. Analysis of future changes in surface pressure does reveal somewhat stronger reductions in surface pressure in the Amazon region, and stronger increases in the western and southern part of South America, in ACCESS1-0 compared to CCSM4 and CESM (Supplementary Fig. S4). However, differences between WRF $50 \mathrm{~km}$ simulations and their driving GCM are again relatively small.

For central Chile, the projected precipitation reductions are consistent between the CMIP5 and CMIP6 multimodel mean, the three GCMs used for downscaling, and the WRF simulations at both 50 and $10 \mathrm{~km}$ horizontal resolution (Fig. 4a, b). WRF results at $10 \mathrm{~km}$ show reductions of 5-20\% in WRF_CCSM4 and WRF_CESM, and 40-50\% in WRF_ACC, with the exception of the northernmost part of the domain which shows a precipitation increase in WRF ACC. The strong precipitation increase in the east/northeast part of the domain in WRF_ACC is mainly due to enhanced convective precipitation (not shown). While this increase is much less noticeable in absolute precipitation amounts, enhanced convective precipitation is also projected in summer and this could potentially be important due to the very low precipitation amounts during this season in the historical period. Precipitation reductions in central Chile are also projected for the middle-of-the-century RCP4.5 for the CMIP5 multi-model mean (Supplementary Fig. S5), and for CESM and WRF_CESM (Supplementary Fig. S6), though with weaker magnitudes due to a smaller climate change signal compared to that in the end-of-the-century RCP8.5. Thus, expectations of a future reduction in precipitation in central Chile can be seen as a robust result.

The CMIP5 and CMIP6 multi-model means show a future increase in precipitation in Peru, except near the border of Brazil (Fig. 4a). The CMIP5 models do not agree on the sign of the change, indicating model diversity. The three GCM simulations used for downscaling agree with the multimodel mean, of a future precipitation increase in most of Peru (Fig. 4c). However, the WRF simulations at $50 \mathrm{~km}$ horizontal resolution differ from their driving GCMs and show very different patterns of precipitation change over Peru. The higher resolution in WRF compared to the GCMs leads to a more inhomogeneous pattern in the precipitation changes, 
(a)
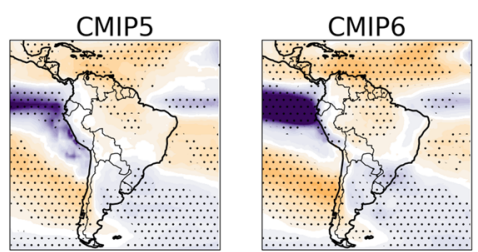

ACCESS1-0
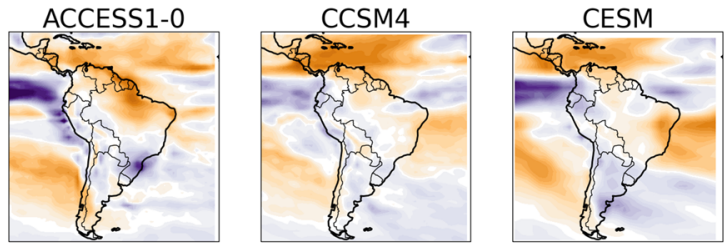

WRF ACC $50 \mathrm{~km}$
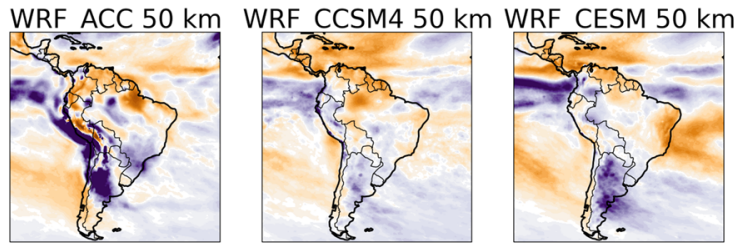

(c)
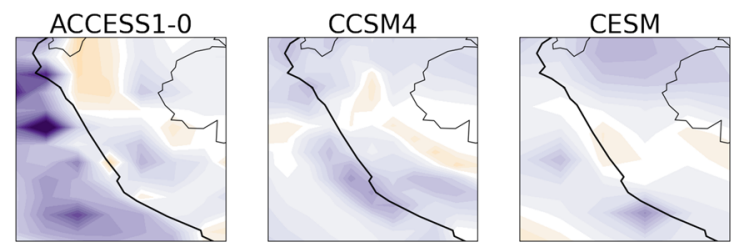

WRF ACC $50 \mathrm{~km}$
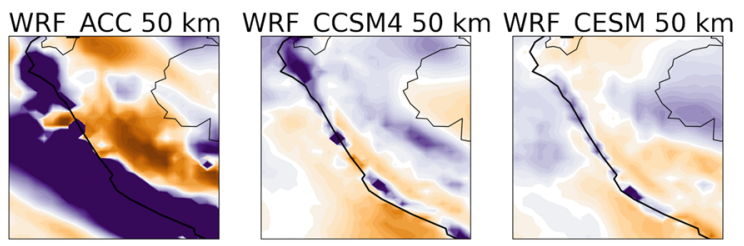

WRF ACC $10 \mathrm{~km}$
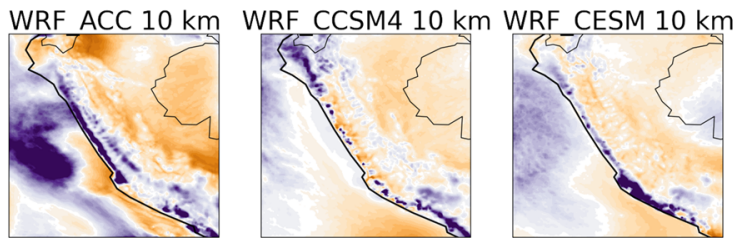

(b)
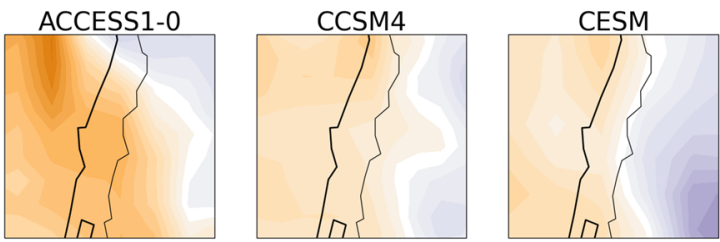

WRF ACC $50 \mathrm{~km}$
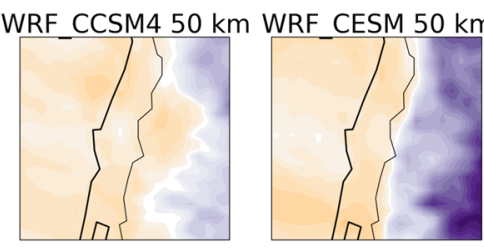

WRF_CCSM4 $10 \mathrm{~km}$ WRF_CESM $10 \mathrm{~km}$
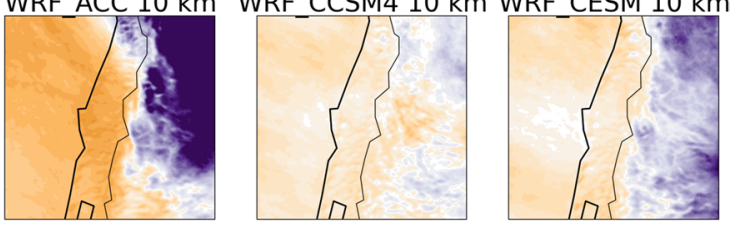

(d)
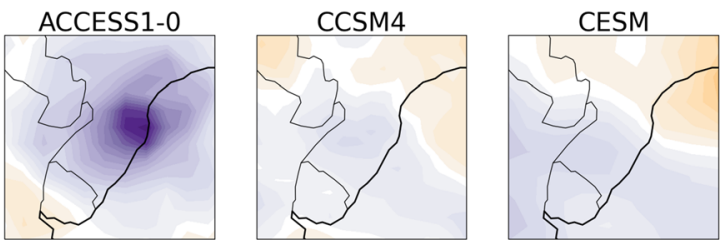

WRF ACC $50 \mathrm{~km}$
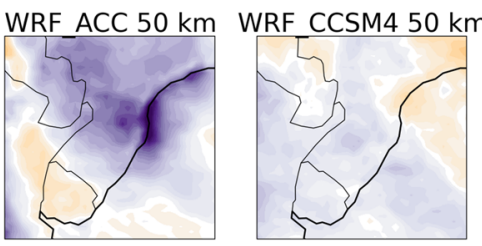

WRF CESM $50 \mathrm{~km}$

WRF ACC $10 \mathrm{~km}$

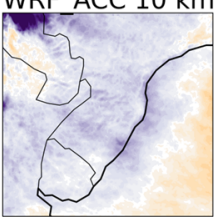

WRF CCSM4 $10 \mathrm{~km}$ WRF CESM $12 \mathrm{~km}$
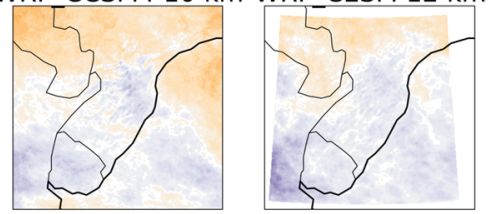

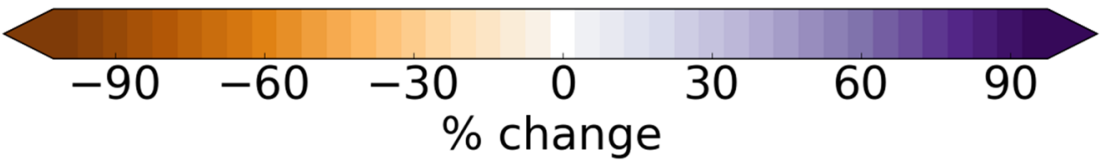

Fig. 4 Projected changes in annual precipitation (\%) in 1996-2005 vs. 2091-2100 (RCP8.5) for a South America, b central Chile, c Peru and d southern Brazil. Stippling in the CMIP5 and CMIP6 plots in (a) indicates where more than $80 \%$ of the models agree on the sign of change

and the choice of resolution could be of major importance for this region governed by orographic precipitation. The precipitation change patterns are further refined in $10 \mathrm{~km}$ resolution and now broadly agree between the different WRF simulations downscaled from three GCMs. In contrast to the GCMs, all three WRF simulations show that precipitation increases are confined to a narrow band on the Pacific side of the Andes Mountains, while a more widespread precipitation decrease is simulated inland. Furthermore, the inland precipitation changes differ between the 50 and $10 \mathrm{~km}$ resolution simulations. Results for WRF_CESM for mid-century RCP4.5 show almost the same pattern of precipitation change, but magnitudes are weaker (Supplementary Fig. S6). A likely cause of the differences in precipitation change patterns between the resolutions is the better representation of 
the complex orography in the higher resolution simulations, and this is investigated further in Sect. 3.2.3.

In southern Brazil, the multi-model CMIP5 and CMIP6 means show a future precipitation increase, both for midcentury RCP4.5 and end-of-the-century RCP8.5 (Fig. 4a; Supplementary Fig. S5). The three GCM simulations agree on a future precipitation increase in southern Brazil, but CCSM4 and CESM show a precipitation reduction in the northern part of the domain, in contrast to ACCESS1-0 (Fig. 4d). The WRF $50 \mathrm{~km}$ resolution simulations largely agree with projections from the GCMs used as boundary conditions, highlighting the strong influence of the driving model for the downscaled results. As for the Peru region, there are noticeable differences when moving towards high resolution. All three WRF $10 \mathrm{~km}$ simulations show lower precipitation increases in southern Brazil compared with the $50 \mathrm{~km}$ WRF simulations and their driving GCMs. Interestingly, the WRF_CESM $10 \mathrm{~km}$ simulation for the midcentury RCP4.5 show a precipitation reduction in most of southern Brazil (Supplementary Fig. S6).

\subsubsection{Future changes in the seasonal precipitation cycle}

Figure $3 b$ shows the projected change in the seasonal precipitation cycle from the GCMs and WRF, averaged over each region in Fig. 4. For the central Chile domain, a future precipitation reduction is projected for most of the year and the different WRF simulations agree well with the projections of their driving GCM, both in terms of monthly amounts and temporal distribution. In austral summer, CESM and WRF_CESM show a precipitation increase, and this can be attributed to the projected precipitation increase in Argentina (Fig. 4b).

In contrast to the Chile region, the seasonal precipitation change in Peru projected by the WRF model at $10 \mathrm{~km}$ horizontal resolution differs to that projected by WRF at $50 \mathrm{~km}$ resolution (Fig. 3b). The WRF simulations also differ from their driving GCM simulations. This shows that it is not only the spatial pattern of precipitation change that differs between the resolutions, as discussed in Sect. 3.2.1, but also the magnitude of change and how the precipitation is distributed throughout the year. Most of the WRF $10 \mathrm{~km}$ simulations show the strongest absolute precipitation reductions in August to October, but the WRF_ACC simulation also show strong reductions in the last part of the year. GPCC observations and simulations show that the rainy season lasts from around August to April (Fig. 3a), but the projected changes in the WRF $10 \mathrm{~km}$ simulations are relatively small early in the year, especially for WRF_CESM (Fig. 3b). In the WRF $50 \mathrm{~km}$ simulations and the three GCM simulations, precipitation increases are projected mostly in the first few months of the year. The fact that the major differences in precipitation change between resolutions are occurring during austral summer, when precipitation is dominated by convective precipitation, may indicate that the convection parameterization scheme could be a potential source for the differences.

In southern Brazil, the choice of driving GCM seems more important than the choice of horizontal model resolution for changes in the regionally-averaged seasonal precipitation cycle (Fig. 3b). While the projected precipitation changes in WRF_CCSM4 and WRF_CESM have different sign between many of the months, WRF_ACC shows increased precipitation throughout the year, except February to April in the $10 \mathrm{~km}$ simulation. However, in all WRF simulations there is a tendency of less increase, or more reduction, of precipitation when going from 50 to $10 \mathrm{~km}$ resolution, similarly to what was found for the Peru region. Possible causes for these differences are discussed in Sect. 3.3.

\subsubsection{Sensitivity simulations to understand model differences for Peru}

Table 2 lists the sensitivity simulations that have been carried out to better understand the large differences in projected precipitation changes in Peru between the WRF simulations using 50 and $10 \mathrm{~km}$ horizontal model resolution, as described in Sects. 3.2.1-3.2.2. Due to the complex orography of the Andes Mountains, one potential reason for these differences is that precipitation, and particularly orographic precipitation, is better resolved in the $10 \mathrm{~km}$ resolution than the $50 \mathrm{~km}$ resolution due to the finer representation of elevation in the first. This has been investigated in the WRF_CCSM4_topo simulation, a $10 \mathrm{~km}$ simulation where orography has been smoothed to $50 \mathrm{~km}$ resolution (maps of the smoothed and unsmoothed topography are shown in Supplementary Fig. S7). Another potential cause is that the $10 \mathrm{~km}$ result is inaccurate because the domain is too small. Although an outer boundary of 10 grid boxes has been removed for the analysis, it may be necessary with a wider boundary because of the mountains extending well outside of the domain. A sensitivity simulation, WRF_CCSM4 large, has been performed with a much larger $10 \mathrm{~km}$ domain, D3large, which is 2-3 times larger than D3 (Fig. 1).

Parameterization of convection has been identified as a major source of uncertainty in future climate projections by global and regional models (Kendon et al. 2017; Prein et al. 2015). So-called "convection-permitting modelling", where deep convection is explicitly resolved, has shown to improve modelling of the diurnal precipitation cycle and precipitation occurrence, but require vast computational resources. Typically, a horizontal model resolution smaller than $4 \mathrm{~km}$ is considered necessary to resolve deep convection (Prein et al. 2015). However, recent findings show that turning off the deep convection parameterization scheme may be beneficial up to around $25 \mathrm{~km}$ model resolution (Vergara-Temprado 
et al. 2020). For this reason we have turned off the deep convection parameterization scheme in the $10 \mathrm{~km}$ resolution domain in the simulation WRF_CCSM4_noCP (Table 2), to see if this impacts the precipitation projection. In a separate simulation, WRF_CCSM4_cpGF, we have tested the effect of using a different deep convection parameterization scheme. Here, the Kain-Fritsch scheme (Kain 2004) was replaced by the Grell-Freitas ensemble scheme (Grell and Freitas 2014) in both the 50 and $10 \mathrm{~km}$ resolution domains. While the Kain-Fritsch scheme is a mass flux parameterization, the Grell-Freitas scheme is based on a stochastic approach and has shown to work well for simulations with varying horizontal resolutions (Gao et al. 2017; Jeworrek et al. 2019).

Figure 5 shows the projected precipitation change averaged over the Peru domain for the different 3-year sensitivity simulations. For the CCSM4 and WRF_CCSM4 simulations, where the full 10 years are available, we see that the 3 -year averages are representative of the 10-year averages (black vs. open diamonds). Maps of the 10-year vs. 3-year average precipitation change reveal that the spatial distribution of the changes is also similar (not shown). In four of the sensitivity simulations, changes have only been made to the $10 \mathrm{~km}$ resolution domain and results in $50 \mathrm{~km}$ resolution are therefore approximately equal. Interestingly, the change in non-convective precipitation has the same sign in all WRF simulations and at both resolutions while the convective precipitation change differs substantially. By replacing the Kain-Fritsch convection parameterization scheme with the Grell-Freitas scheme (purple bars), the sign is switched for convective precipitation change in $50 \mathrm{~km}$ resolution and now shows similar results as in $10 \mathrm{~km}$ resolution, although with a smaller magnitude. Switching off the convection parameterization scheme did not have a strong impact on the results other than a smaller precipitation reduction in $10 \mathrm{~km}$ (orange bar compared to blue bar), which presumably is related to less precipitation in the historical (1996-1998) simulation when the scheme is deactivated (not shown). The result that switching off the convection parameterization scheme gives a similar, although slightly smaller, projected precipitation change as the $10 \mathrm{~km}$ simulations with the parameterization scheme enabled, gives confidence that we can trust the $10 \mathrm{~km}$ results that have the convection scheme turned on.

Surprisingly, smoothing of the terrain height field in the WRF_CCSM4_topo simulation (red bar in Fig. 5) did not have a noticeable impact on the results, other than changing the partitioning of convective vs. non-convective precipitation change. The precipitation change in Peru when increasing the extent of the high-resolution $(10 \mathrm{~km})$ domain (green bar), also only had a small impact on the results.

\subsubsection{Future changes in daily extreme precipitation}

A common metric for extreme precipitation is Rx 1 day, which is the annual maximum 1-day precipitation amount (Alexander 2016). 10-year means of the historical (1996-2005) Rx1day amounts differ strongly between the GCMs and WRF, and between 50 and $10 \mathrm{~km}$ WRF resolutions (Supplementary Fig. S8). Whereas the mean of GCMs do not show more than $75 \mathrm{~mm} \mathrm{day}^{-1}$ in any of the three regions, WRF at
Fig. 5 Projected changes in annual precipitation $\left(\mathrm{mm} \mathrm{day}^{-1}\right)$ in $1996-1998$ vs. $2091-2093$ (RCP8.5) for the Peru region (D3 in Fig. 1, both land and sea gridpoints) for different simulations and horizontal model resolutions. 3-year averages of total precipitation changes (black diamonds) have been split into convective (dark coloured bars) and nonconvective (light coloured bars) precipitation. Total precipitation changes for the full 10-year periods (open diamonds) are shown for comparison when available. Error bars show the standard deviation representing the interannual spread

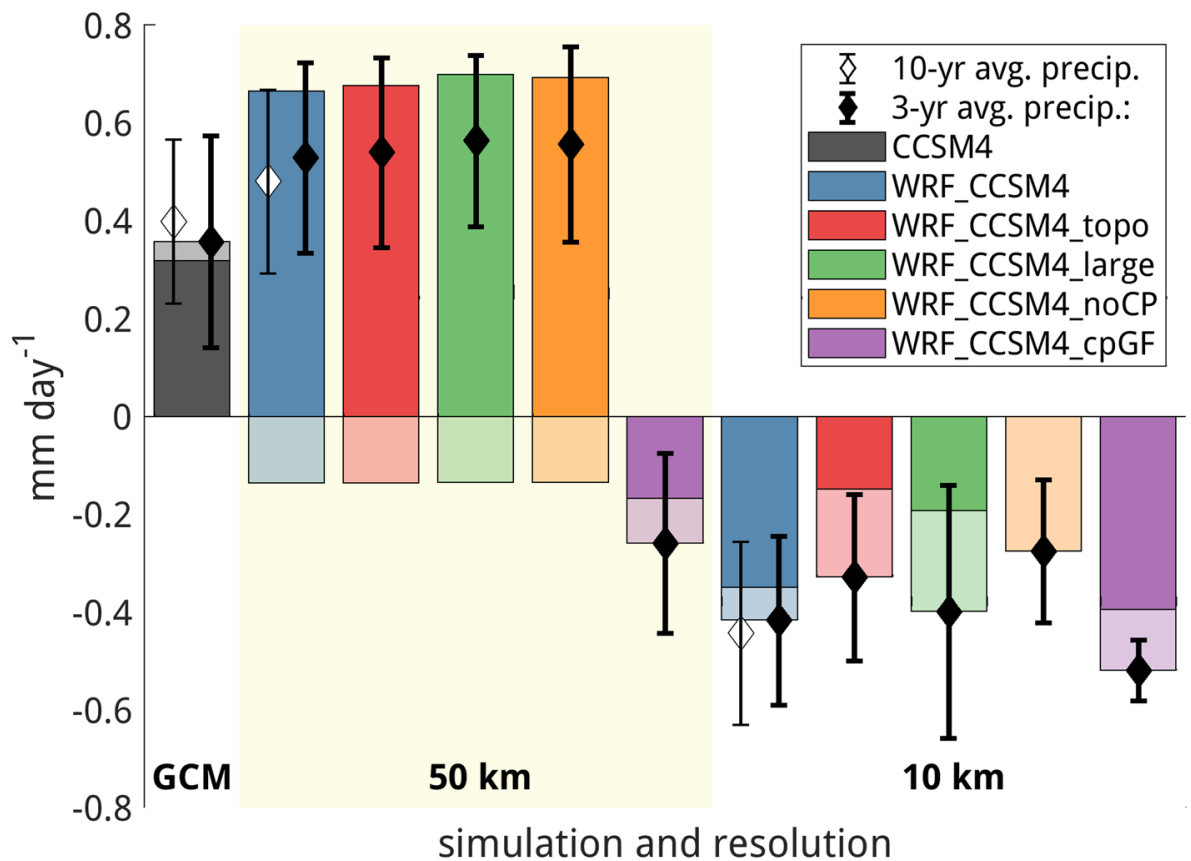


$10 \mathrm{~km}$ resolution exceeds $200 \mathrm{~mm} \mathrm{day}^{-1}$ in some locations in the Andes, both in the central Chile and Peru regions.

Figure 6 shows future changes in Rx1day, averaged over the three GCMs and WRF simulations. Despite the strong model agreement of a future precipitation reduction over central Chile (Sect. 3.2.1), there is no such agreement for Rx1day change, and both the GCMs and the WRF simulations differ in the sign of change. Decreases in mean precipitation combined with relatively unchanged daily extreme precipitation have also been projected before in other regions (e.g., Hodnebrog et al. 2019), and is related to the fact that daily extreme precipitation increases more than annual mean precipitation on a global scale ( $7 \%$ vs. $1-3 \%$ per degree global warming, respectively) (Allen and Ingram 2002; Boucher et al. 2013).

For Peru, the GCMs agree on an increase in Rx1day, with a model mean typically in the range $20-30 \%$ (Fig. 6). However, after downscaling with WRF, the diversity is larger and only parts of Peru show consistent Rx1day increases. For southern Brazil, the projected increase in Rx1day by the GCMs largely persists also in the downscaled WRF simulations.

Potential changes in dry conditions could be particularly important for water availability and have been analyzed here in terms of the annual number of dry days (days with precipitation $<1 \mathrm{~mm}$ ). The three regions show very different patterns with $<100$ dry days in some inland regions of Peru and $>250$ dry days along the coast of Peru and in central Chile (Supplementary Fig. S9).

Figure 7 shows future changes in the number of dry days, and for central Chile there is a projected increase of 10-30 days, which is consistent between the GCMs and WRF at 50 and $10 \mathrm{~km}$ resolution. For Peru, there is also an overall increase projected for the future, but this is much more prominent in the WRF $10 \mathrm{~km}$ resolution simulations than in WRF at $50 \mathrm{~km}$ and in the GCMs. There are only weak changes in the number of dry days over southern Brazil, and with much less agreement on the sign of change. (a)

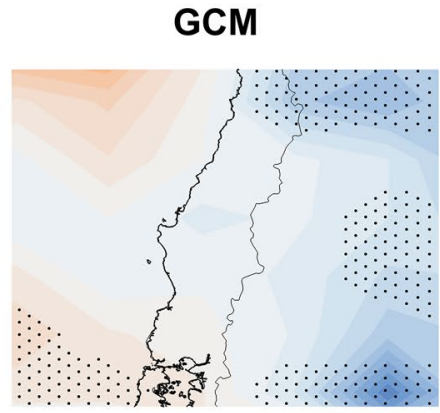

(b)

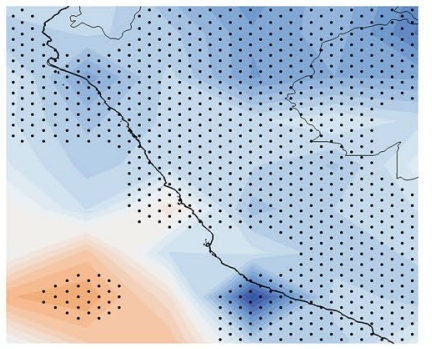

(c)

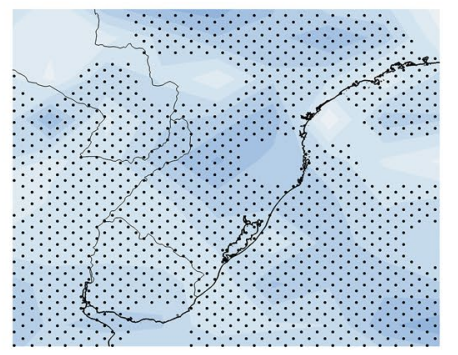

WRF $50 \mathrm{~km}$
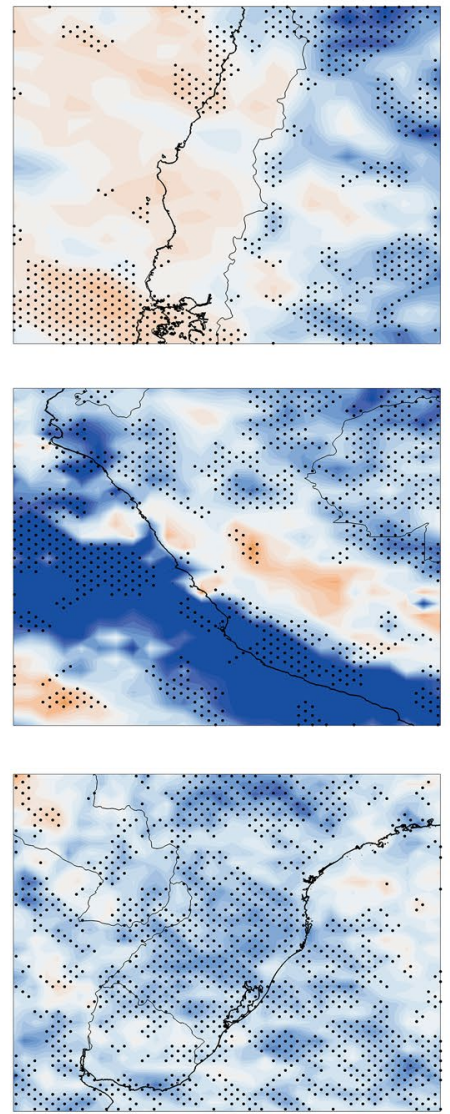

WRF $10 \mathrm{~km}$
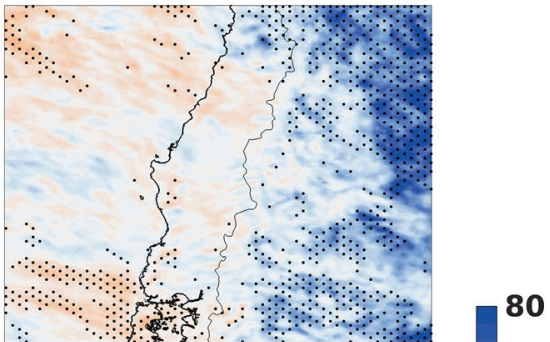

60

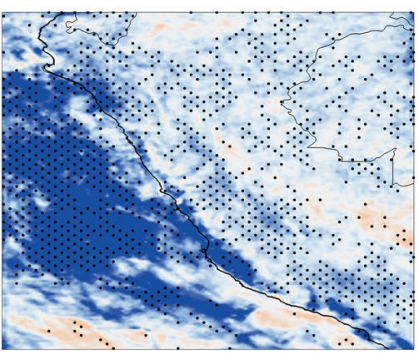

40

20

$0 \%$

$-20$

$-40$

$-60$

$-80$
Fig. 6 Projected relative changes in Rx1day daily extreme precipitation (\%) in 1996-2005 vs. 2091-2100 (RCP8.5) for a central Chile, b

Peru and $\mathbf{c}$ southern Brazil. Results are averaged over the three GCM/
WRF simulations CESM/WRF_CESM, CCSM4/WRF_CCSM4 and ACCESS1-0/WRF_ACC. Stippling indicates where model simulations agree on the sign of change 
(a)

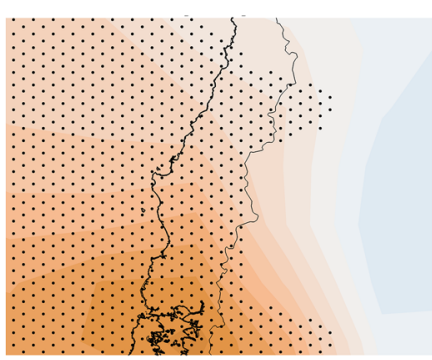

(b)

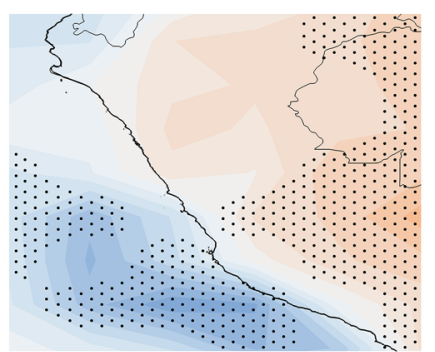

(c)

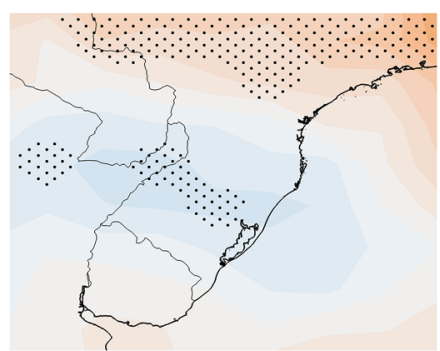

WRF 50 km
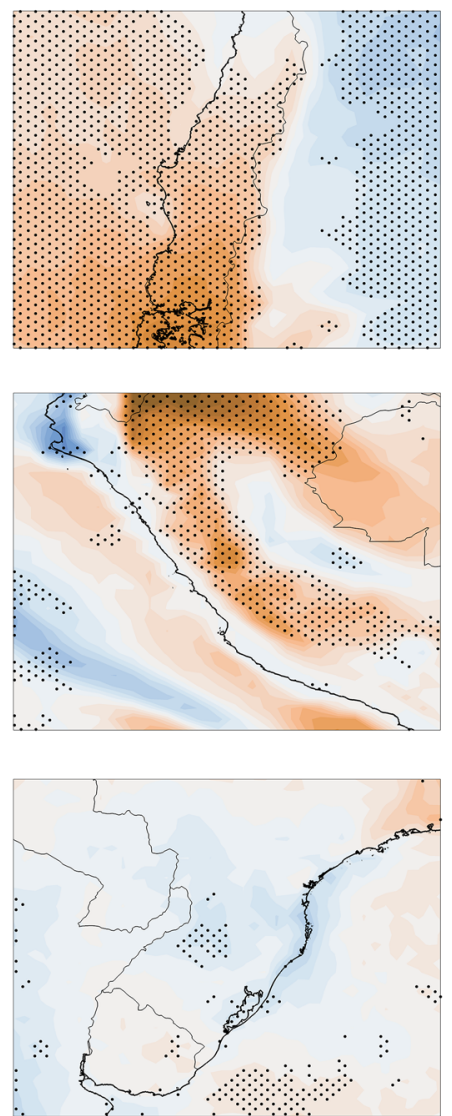

WRF $10 \mathrm{~km}$

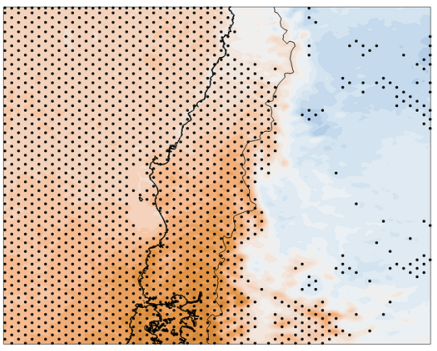

60

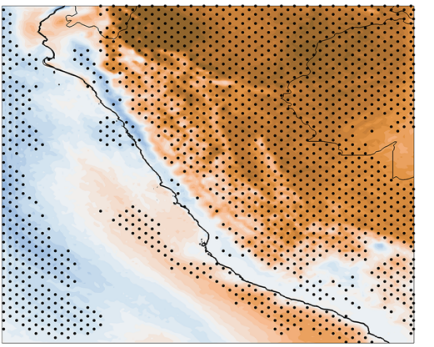

40

20

$0 \stackrel{\frac{n}{2}}{\frac{\pi}{0}}$

$-20$

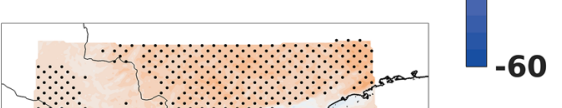

60

Fig. 7 Projected absolute changes in the annual number of dry days in 1996-2005 vs. 2091-2100 (RCP8.5) for a central Chile, b Peru and c southern Brazil. Results are averaged over the three GCM/
WRF simulations CESM/WRF_CESM, CCSM4/WRF_CCSM4 and ACCESS1-0/WRF_ACC. Stippling indicates where model simulations agree on the sign of change

\subsection{Atmospheric energy budget analysis}

Figure 8 shows the atmospheric energy budget according to Eq. (1) (see Sect. 2.6). Differences in precipitation changes between regions, model simulations and resolutions can mainly be attributed to the $H_{\text {dry }}$ and $M$ terms, but also with smaller contributions from $\mathrm{SH}$ and $\mathrm{LH}$. In all three regions and for all model resolutions, the three different model simulations agree well for the atmospheric shortwave and longwave radiative cooling terms. Increased surface temperature as a result of increased $\mathrm{CO}_{2}$ concentrations is the main driver for changes in the perturbed climate. As explained in Richardson et al. (2018a), the surface warming from higher $\mathrm{CO}_{2}$ concentrations lead to increased longwave radiative cooling (i.e. positive LW term in Fig. 8). Globally, the atmospheric radiative cooling from increased troposheric temperature is more than compensated by stratospheric temperature reduction. Increased water vapour from increased atmospheric temperatures leads to longwave and shortwave radiative heating (reducing precipitation). Furthermore, clouds may cause both radiative heating and cooling depending on the altitude of the clouds. Inspection of our WRF results confirms an increase in atmospheric temperature and humidity over South America in the future simulation, but also reveal important changes in clouds (Supplementary Fig. S10), which also influence the energy budget fluxes. The projected cloud changes over South America, with reduced low and middle level clouds and increased high clouds, agree with multi-model results of global cloud changes caused by increases in atmospheric $\mathrm{CO}_{2}$ concentrations (e.g., Fig. 1 in Hodnebrog et al. 2020).

For central Chile, differences between the GCM results and WRF in 50 and $10 \mathrm{~km}$ resolution are relatively small (Fig. 8). The spatial pattern of changes in $P$ is also similar between the two WRF resolutions, except for a more inhomogeneous pattern in $10 \mathrm{~km}$ resolution (Supplementary Fig. S11). The precipitation reduction $(P<0)$ can be explained by less moisture transported into the region $(M<0)$, but $P$ is slightly modulated by increased evaporation within the region $(\mathrm{LH}>0)$ (Fig. 8). Differences between the 

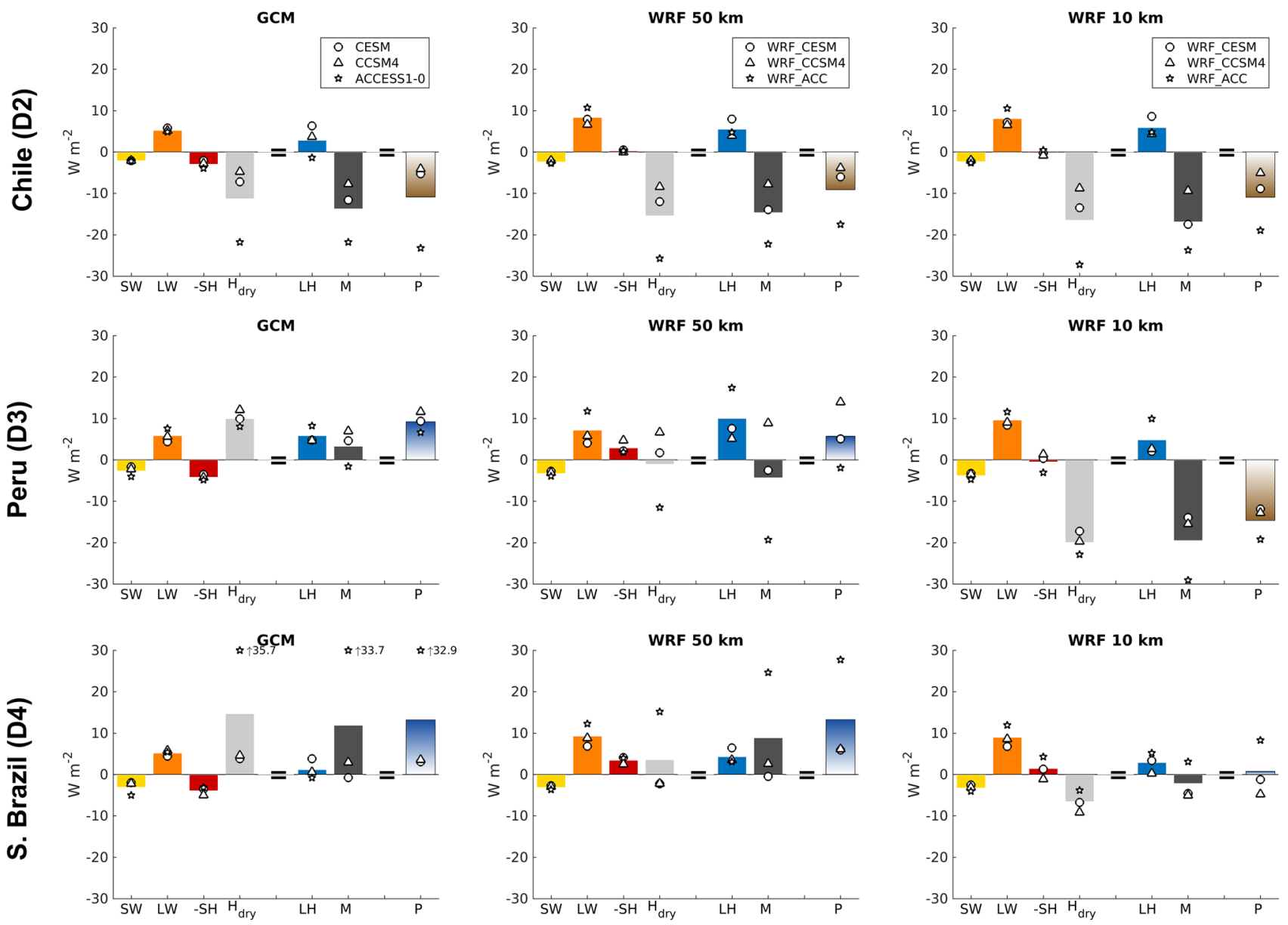

Fig. 8 Atmospheric energy budget for the three focus regions (both land and sea gridpoints). Markers show results for the individual model simulations and bars represent the mean. Positive values denote atmospheric cooling, which means increased precipitation

simulations are larger, however, and $H_{\mathrm{dry}}$ and $M$ are more negative for ACCESS1-0 and WRF_ACC compared to the other simulations.

For Peru, the different GCM simulations agree on the sign and approximate magnitude for each of the terms in the atmospheric energy budget (Fig. 8). There is a small exception for the $M$ term, which is slightly negative for ACCESS1-0 and positive for CESM and CCSM4. In the $50 \mathrm{~km}$ resolution WRF simulations, there is a large spread for several of the budget terms, most notably for $H_{\text {dry }}$ and $M$, with the latter having a range from about $-20 \mathrm{~W} \mathrm{~m}^{-2}$ (WRF_ACC) to $+10 \mathrm{~W} \mathrm{~m}^{-2}$ (WRF_CCSM4). While all three model simulations agree on more evaporation in the future $(\mathrm{LH}>0)$, there is considerable uncertainty regarding how much of the moisture that will end up as precipitation within the region and how much that will be transported out of the region. It is also interesting to note that the $\mathrm{SH}$ term switches sign between the GCMs and their downscaled $(50 \mathrm{~km}) \mathrm{WRF}$ results. For the $10 \mathrm{~km}$ resolution WRF results, according to Eq. (1), and results are shown for 1996-2005 vs. 20912100 (for CESM and WRF_CESM the time periods are 1986-2005 vs. $2081-2100)$

the three different simulations again tend to agree for most of the terms. However, the results are now very different from their driving GCMs, with net negative moisture convergence $(M<0)$, meaning that more moisture is transported out of than into the region in the future compared to the historical climate. Local evaporation compensates only partly for this moisture reduction and $P$ is therefore negative.

Analysis of the Peru sensitivity simulations presented in Sect. 3.2.3 shows that the difference in projected precipitation change between the resolutions is related to the parameterization of convection. The very different value of $H_{\mathrm{dry}}$ between the resolutions (Fig. 8) strongly indicates that there are differences in horizontal and/or vertical winds. Figure 9 shows that there are strong differences in the vertical velocities at $\sim 500 \mathrm{hPa}(W)$ between the resolutions. The ascending air masses in the northeast strengthen in the future in $50 \mathrm{~km}$ resolution, while they weaken in $10 \mathrm{~km}$ resolution. This region is also the area where the difference in absolute precipitation change is the largest between the resolutions, 


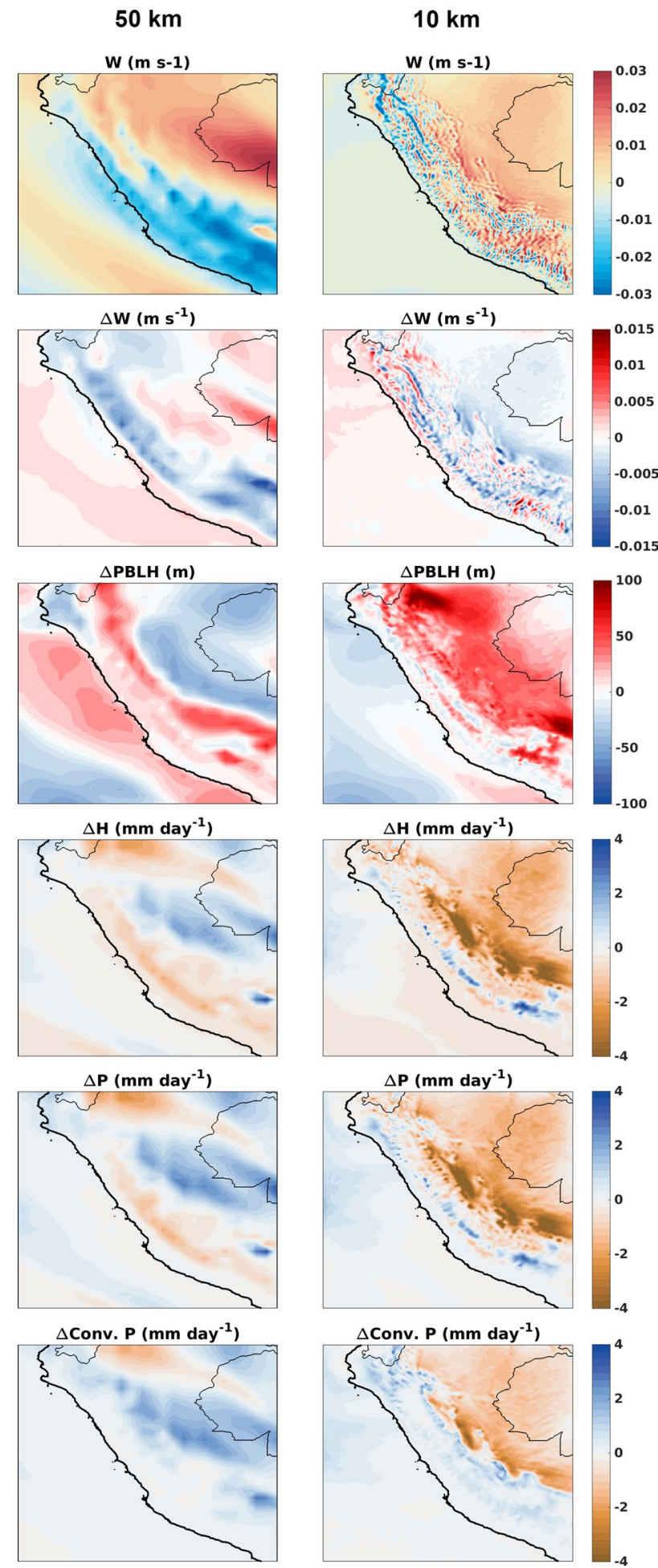

Fig. 9 Annual mean vertical velocity at $\sim 500 \mathrm{hPa}\left(W\right.$ in $\left.\mathrm{m} \mathrm{s}^{-1}\right)$ and projected changes in vertical velocity $(\Delta W)$, planetary boundary layer height $(\triangle \mathrm{PBLH}$ in $\mathrm{m})$, dry static energy flux divergence $(\Delta H$ in $\mathrm{mm}$ day $^{-1}$; see Eq. 1), total precipitation $\left(\Delta P\right.$ in $\left.\mathrm{mm} \mathrm{day}^{-1}\right)$ and convective precipitation ( $\Delta$ Conv. $\mathrm{P}$ in $\mathrm{mm} \mathrm{day}^{-1}$ ) according to WRF results in 50 and $10 \mathrm{~km}$ horizontal resolution over Peru. Results are averaged over the three simulations WRF_CESM, WRF_CCSM4 and WRF_ ACC and changes are between 1996-2005 and 2091-2100. Results for central Chile and southern Brazil are in Supplementary Fig. S11 and the patterns of change in $H_{\text {dry }}$ are very similar to the precipitation change patterns, which again shows similarities to the pattern of change in convective precipitation. In contrast, only a very small part of the changes in $P$ in the Chile simulations were due to changes in convective precipitation (Supplementary Fig. S11). In the northeast region of the Peru domain, the planetary boundary layer height (PBLH) becomes lower and higher in 50 and $10 \mathrm{~km}$, respectively, in the future, and this is a clear indication of changes in vertical motions since convection is a main driver for changes in the PBLH (Fig. 9).

For southern Brazil, there is a precipitation increase in the GCM simulations, as for Peru, mainly caused by the transport terms ( $M$ and $H_{\text {dry }}$ ) (Fig. 8). However, the intermodel difference is large with CESM and CCSM4 showing small changes $\left(<5 \mathrm{~W} \mathrm{~m}^{-2}\right)$ and ACCESS1-0 large changes $\left(>30 \mathrm{~W} \mathrm{~m}^{-2}\right)$. The large transport and precipitation terms for ACCESS1-0 become much smaller when downscaled with WRF, and especially in $10 \mathrm{~km}$ resolution. Interestingly, all three model simulations have a negative $H_{\text {dry }}$ term in the highest resolution and $P$ differs in sign and magnitude between the three simulations. As for Peru, and in contrast to Chile, the changes in precipitation are mainly due to convective and not large-scale precipitation changes (Supplementary Fig. S11). Since there are no major differences between projected circulation patterns in the WRF simulations at $50 \mathrm{~km}$ resolution and their driving GCM (Supplementary Fig. S4), it is therefore likely that differences between 50 and $10 \mathrm{~km}$ precipitation are connected to the convection parameterization scheme, similarly as for Peru. A main difference between the two resolutions is that the center of the region experiences enhanced ascending air in $50 \mathrm{~km}$, and therefore a positive precipitation change through the $H_{\text {dry }}$ term, while the contribution to increased $P$ due to enhanced ascending air is smaller in the $10 \mathrm{~km}$ resolution results (Supplementary Fig. S11).

\section{Discussions}

Comparison to observations in Sect. 3.1 shows that WRF_ NNRP, which is WRF downscaled from a reanalysis dataset, generally performs well for all three regions, indicating that the chosen setup is sound. The performance for WRF when using initial and boundary conditions from GCMs is more variable, but this is to be expected since the GCMs are freerunning (i.e. no assimilation of observations) and the quality of regional climate modelling is conditional on the quality of the boundary conditions (e.g. Rummukainen 2010).

The difference between results with WRF using CCSM4 and CESM is relatively small. While this can partly be expected because the two models are very similar, their setups differ in terms of horizontal model resolution and 
spin-up length when used to drive WRF (see Sect. 2.3-2.4 for details). The relatively similar precipitation change patterns in WRF_CCSM4 and WRF_CESM, shown in Fig. 4, further indicate that there is a strong signal-to-noise ratio and relatively small influence of natural variability.

The projected precipitation changes using WRF in $50 \mathrm{~km}$ resolution agree well, qualitatively, with those projected by the RCM simulations in Llopart et al. (2020) (different units and time periods hinder a quantitative comparison of the two studies), e.g. with reduced precipitation in central Chile and a slight increase in southern Brazil (Fig. 4b, d vs. their Figs. 4b, 5b). For Peru, the increase during DJF and slight decrease during JJA projected by the RCMs in Llopart et al. (2020) is also found in WRF $50 \mathrm{~km}$ resolution (Fig. 3b). Our finding that the increase in precipitation for Peru is smaller in WRF $50 \mathrm{~km}$ resolution than in the GCMs (e.g. Figure 4a) is also reflected in the Llopart et al. results (their Figs. 4, 5). However, we also show that the convection parameterization appears to be a more important factor than the spatial resolution of the orography in affecting precipitation projections for the region.

Previous studies have highlighted the importance of the $\mathrm{CO}_{2}$ physiological effect for precipitation changes in South America, through reduced evapotranspiration from plants due to reduced stomatal conductance at elevated $\mathrm{CO}_{2}$ concentrations (e.g. Langenbrunner et al. 2019). While the physiological effect is most important for the eastern Amazon, where it is the main driver of future drying, it has also shown to increase precipitation along the west coast of South America, including Peru (Richardson et al. 2018b; Skinner et al. 2017). Future studies should carry out high-resolution RCM simulations with the physiological effect included for long (climatological) time scales, to reduce uncertainties associated with projected precipitation changes in South America.

\section{Summary and conclusions}

To better understand projected precipitation changes in South America, historical and future climate model simulations from three GCMs have been downscaled and analysed in terms of changes in the atmospheric energy budget. The regional model $\mathrm{WRF}$ has been used at $50 \mathrm{~km}$ horizontal resolution for the whole continent and at $10 \mathrm{~km}$ resolution over three focus regions: central Chile, Peru and southern Brazil. A reference WRF simulation with reanalysis data (NNRP) as initial and boundary conditions is able to reproduce historical (1996-2005) precipitation patterns and seasonal cycles from a gridded observation data set (GPCC) and a high-resolution $(\sim 9 \mathrm{~km})$ reanalysis data set (ERA5Land). The performance of the WRF simulations using the GCMs as initial and boundary conditions is more variable but still relatively good, and indication of added value when going from 50 to $10 \mathrm{~km}$ horizontal resolution is particularly evident in the spatial precipitation distribution over Peru for WRF downscaled from the ACCESS1-0 GCM.

Future simulations (2091-2100) assuming a high greenhouse gas emission scenario (RCP8.5) show reductions in annual precipitation in central Chile. This is considered a robust result because of good agreement between different CMIP5 and CMIP6 models and between different horizontal model resolutions down to $10 \mathrm{~km}$. The good agreement is also reflected in the atmospheric energy budget, which is very similar across resolutions. An additional WRF simulation downscaled from the CESM GCM for the mid-century (2041-2060), assuming a less greenhouse gas intensive scenario ( $\mathrm{RCP} 4.5)$, shows a very similar precipitation reduction but with a smaller magnitude.

For Peru, precipitation projections from GCMs generally agree on an increase in the future (2091-2100RCP8.5). However, the different WRF simulations in $50 \mathrm{~km}$ resolution, downscaled from the three different GCM simulations, disagree on the sign of the precipitation change. The $10 \mathrm{~km}$ WRF simulations, on the other hand, agree on a future precipitation reduction over Peru. Sensitivity simulations show that the more detailed representation of orography, in this mountainous region, does not cause the strong difference in precipitation projections between 50 and $10 \mathrm{~km}$ resolution, but that differences are rather linked to parameterization of convective precipitation. Future changes in vertical velocity and planetary boundary layer height differ strongly between resolutions and, in particular, enhanced (weakened) ascending air masses east of the Andes Mountains in $50 \mathrm{~km}$ $(10 \mathrm{~km})$ resolution leads to increased (decreased) precipitation in this region. Analysis of the atmospheric energy budget confirms that differences between resolutions are related to transport, e.g. with strongly net negative moisture convergence in $10 \mathrm{~km}$ resolution, meaning that more moisture is transported out of than into the region in the future compared to the historical climate.

In southern Brazil, precipitation increases are projected for the future (2091-2100RCP8.5) from the CMIP5 and CMIP6 model ensembles, the three selected GCMs and $\mathrm{WRF}$ at $50 \mathrm{~km}$ resolution. However, there is considerable model diversity and precipitation changes are small in the $10 \mathrm{~km}$ resolution WRF simulations. The mid-century projection (2041-2060RCP4.5) with WRF_CESM even shows a small reduction in precipitation. As for Peru, this is linked to different representation of convective precipitation between the resolutions and the atmospheric energy budget shows that the dry static energy term switches sign for all three models between the GCM and WRF $10 \mathrm{~km}$ resolution simulations.

In conclusion, this study provides future high-resolution precipitation projections and explains reasons for future 
changes in regions where such detailed climate projections currently are lacking. While high model resolution has been deemed important for projections of summertime extreme precipitation at midlatitudes (Kendon et al. 2017), this study highlights the importance of using high model resolution when projecting changes in annual precipitation for regions in the sub-tropics and tropics, where convective precipitation constitutes the major share of the total precipitation.

Using results directly from GCMs, and even from coarse resolution RCMs, may give incorrect conclusions about precipitation projections on a regional scale. Ultimately, this may lead to wrongly informed policy-makers, who deals with decisions concerning adaptation to, and mitigation of, climate change. Hence, there is a need for an ensemble of model simulations at high spatial resolution, ideally using convection-permitting modelling, to make reliable precipitation projections for regions dominated by convective precipitation, such as Peru and southern Brazil. While convectionpermitting modelling is still computationally expensive for large regions and/or long time scales, a lot can be gained in coarse-resolution RCM simulations by choosing an appropriate convection parameterization scheme. Our results show that the scale-aware Grell-Freitas convection parameterization scheme applied in WRF at $50 \mathrm{~km}$ resolution is able to reasonably reproduce projected precipitation changes at $10 \mathrm{~km}$ resolution.

Supplementary Information The online version contains supplementary material available at https://doi.org/10.1007/s00382-021-05964-w.

Acknowledgements We acknowledge the World Climate Research Programme, which, through its Working Group on Coupled Modelling, coordinated and promoted CMIP. We thank the climate modelling groups for producing and making available their model output, the Earth System Grid Federation (ESGF) for archiving the data and providing access, and the multiple funding agencies who support CMIP and ESGF. We further acknowledge data providers for the observational datasets.

Author contributions $\varnothing \mathrm{H}$ led the work with the analysis and wrote the first draft, with particular input from BMS and GM. ØH, GM and SBD designed the study. $\varnothing \mathrm{H}, \mathrm{BMS}$ and LM performed WRF simulations. $\varnothing \mathrm{H}, \mathrm{BMS}, \mathrm{KA}$ and SBD analyzed observations. All authors gave input in the writing process.

Funding The work has received support from the project HYPRE (Grant No. 243942), mainly funded by the Research Council of Norway (RCN) and partly by Statkraft, and from the RCN project GREAT (Grant No. 275589). Computing resources from Notur (NN9188K) and storage resources from Nird (NS9252K) are acknowledged.

Availability of data and material The observation data are available at https://doi.org/10.5676/DWD_GPCC/FD_M_V2018_025 (GPCC), https://doi.org/10.7289/V5D21 VHZ (GHCN-Daily) and http://hidro web.ana.gov.br (Hidroweb). The CMIP5 and CMIP6 model data are available at https://esgf-node.llnl.gov/, selected CESM data at https:// doi.org/10.11582/2019.00027 and the WRF model output at https:// doi.org/10.11582/2021.00067.

\section{Declarations}

Conflict of interest The authors declare no competing interests.

Open Access This article is licensed under a Creative Commons Attribution 4.0 International License, which permits use, sharing, adaptation, distribution and reproduction in any medium or format, as long as you give appropriate credit to the original author(s) and the source, provide a link to the Creative Commons licence, and indicate if changes were made. The images or other third party material in this article are included in the article's Creative Commons licence, unless indicated otherwise in a credit line to the material. If material is not included in the article's Creative Commons licence and your intended use is not permitted by statutory regulation or exceeds the permitted use, you will need to obtain permission directly from the copyright holder. To view a copy of this licence, visit http://creativecommons.org/licenses/by/4.0/.

\section{References}

Alexander LV (2016) Global observed long-term changes in temperature and precipitation extremes: a review of progress and limitations in IPCC assessments and beyond. Weather Clim Extrem 11:4-16. https://doi.org/10.1016/j.wace.2015.10.007

Allen MR, Ingram WJ (2002) Constraints on future changes in climate and the hydrologic cycle. Nature 419:224-232. https://doi.org/10. 1038/nature01092

Alvarez MS, Vera CS, Kiladis GN, Liebmann B (2016) Influence of the Madden Julian oscillation on precipitation and surface air temperature in South America. Clim Dyn 46:245-262. https://doi.org/ 10.1007/s00382-015-2581-6

Alvarez-Garreton C et al (2018) The CAMELS-CL dataset: catchment attributes and meteorology for large sample studies-Chile dataset. Hydrol Earth Syst Sci 22:5817-5846. https://doi.org/10.5194/ hess-22-5817-2018

Ambrizzi T, Reboita MS, da Rocha RP, Llopart M (2019) The state of the art and fundamental aspects of regional climate modeling in South America. Ann NY Acad Sci 1436:98-120. https://doi.org/ 10.1111/nyas. 13932

Avila A, Justino F, Wilson A, Bromwich D, Amorim M (2016) Recent precipitation trends, flash floods and landslides in southern Brazil. Environ Res Lett 11:13. https://doi.org/10.1088/1748-9326/ $11 / 11 / 114029$

Barreiro M, Sitz L, de Mello S, Franco RF, Renom M, Farneti R (2019) Modelling the role of Atlantic air-sea interaction in the impact of Madden-Julian oscillation on South American climate. Int J Climatol 39:1104-1116. https://doi.org/10.1002/joc.5865

Becker A, Finger P, Meyer-Christoffer A, Rudolf B, Schamm K, Schneider U, Ziese M (2013) A description of the global land-surface precipitation data products of the Global Precipitation Climatology Centre with sample applications including centennial (trend) analysis from 1901-present. Earth Syst Sci Data 5:71-99. https:// doi.org/10.5194/essd-5-71-2013

Boucher O et al (2013) Clouds and aerosols. In: Stocker TF et al (eds) Climate change 2013: The physical science basis. Contribution of working group I to the fifth assessment report of the intergovernmental panel on climate change. Cambridge University Press, Cambridge and New York, pp 571-658. https://doi.org/10.1017/ CBO9781107415324.016

Boulanger JP et al (2010) A Europe-South America Network for climate change assessment and impact studies. Clim Change 98:307329. https://doi.org/10.1007/s10584-009-9734-8 
Bozkurt D, Rojas M, Boisier JP, Valdivieso J (2018) Projected hydroclimate changes over Andean basins in central Chile from downscaled CMIP5 models under the low and high emission scenarios. Clim Change 150:131-147. https://doi.org/10.1007/ s10584-018-2246-7

Bozkurt D, Rojas M, Boisier JP, Rondanelli R, Garreaud R, Gallardo L (2019) Dynamical downscaling over the complex terrain of southwest South America: present climate conditions and added value analysis. Clim Dyn 53:6745-6767. https://doi.org/10.1007/ s00382-019-04959-y

Bozkurt D, Bromwich DH, Carrasco J, Rondanelli R (2021) Temperature and precipitation projections for the antarctic peninsula over the next two decades: contrasting global and regional climate model simulations. Clim Dyn 56:3853-3874. https://doi.org/10. 1007/s00382-021-05667-2

Cavalcanti IFA et al (2015) Precipitation extremes over La Plata Basin-review and new results from observations and climate simulations. J Hydrol 523:211-230. https://doi.org/10.1016/j. jhydrol.2015.01.028

Collins M et al (2013) Long-term climate change: projections, commitments and irreversibility. In: Stocker TF et al (eds) Climate change 2013: the physical science basis. Contribution of working group I to the fifth assessment report of the intergovernmental panel on climate change. Cambridge University Press, Cambridge, New York, pp 1029-1136. https://doi.org/10.1017/CBO9781107 415324.024

da Silva FDR, Alves JLD, Cataldi M (2019) Climate downscaling over South America for 1971-2000: application in SMAP rainfall-runoff model for Grande River Basin. Clim Dyn 52:681-696. https:// doi.org/10.1007/s00382-018-4166-7

Espinoza JC et al (2020) Hydroclimate of the Andes part i: main climatic features front. Earth Sci 8:20. https://doi.org/10.3389/feart. 2020.00064

Eyring V, Bony S, Meehl GA, Senior CA, Stevens B, Stouffer RJ, Taylor KE (2016) Overview of the Coupled Model Intercomparison Project Phase 6 (CMIP6) experimental design and organization. Geosci Model Dev 9:1937-1958. https://doi.org/10.5194/ gmd-9-1937-2016

Gao Y, Leung LR, Zhao C, Hagos S (2017) Sensitivity of US summer precipitation to model resolution and convective parameterizations across gray zone resolutions. J Geophys Res-Atmos 122:2714-2733. https://doi.org/10.1002/2016jd025896

Garreaud RD (2009) The Andes climate and weather. Adv Geosci 22:3-11. https://doi.org/10.5194/adgeo-22-3-2009

Garreaud RD, Vuille M, Compagnucci R, Marengo J (2009) Presentday South American climate. Paleogeogr Paleoclimatol Paleoecol 281:180-195. https://doi.org/10.1016/j.palaeo.2007.10.032

Gent PR et al (2011) The community climate system model version 4. J Clim 24:4973-4991. https://doi.org/10.1175/2011jcli4083.1

Giorgi F (2019) Thirty years of regional climate modeling: where are we and where are we going next? J Geophys Res-Atmos 124:5696-5723. https://doi.org/10.1029/2018jd030094

Giorgi F, Gutowski WJ (2015) Regional dynamical downscaling and the CORDEX initiative. In: Gadgil A, Tomich TP (eds) Annual review of environment and resources, vol 40. Annual Reviews, Palo Alto, pp 467-490. https://doi.org/10.1146/annurev-envir on-102014-021217

Gonzalez FR, Raval S, Taplin R, Timms W, Hitch M (2019) Evaluation of impact of potential extreme rainfall events on mining in Peru. Nat Resour Res 28:393-408. https://doi.org/10.1007/ s11053-018-9396-1

Grell GA, Freitas SR (2014) A scale and aerosol aware stochastic convective parameterization for weather and air quality modeling Atmos. Chem Phys 14:5233-5250. https://doi.org/10.5194/ acp-14-5233-2014
Gutowski WJ et al (2016) WCRP COordinated Regional Downscaling EXperiment (CORDEX): a diagnostic MIP for CMIP6. Geosci Model Dev 9:4087-4095. https://doi.org/10.5194/ gmd-9-4087-2016

Held IM, Soden BJ (2006) Robust responses of the hydrological cycle to global warming. J Clim 19:5686-5699. https://doi.org/10.1175/ jcli3990.1

Hidroweb (2017) The HidroWeb Portal. http://hidroweb.ana.gov.br. Accessed 31 Oct 2017

Hodnebrog Ø, Myhre G, Forster PM, Sillmann J, Samset BH (2016) Local biomass burning is a dominant cause of the observed precipitation reduction in southern Africa. Nat Commun 7:11236. https://doi.org/10.1038/ncomms 11236

Hodnebrog $\varnothing$ et al (2019) Intensification of summer precipitation with shorter time-scales in Europe. Environ Res Lett 14:124050. https://doi.org/10.1088/1748-9326/ab549c

Hodnebrog $\varnothing$ et al (2020) The effect of rapid adjustments to halocarbons and $\mathrm{N} 2 \mathrm{O}$ on radiative forcing. Npj Clim Atmos Sci 3:43. https://doi.org/10.1038/s41612-020-00150-x

Jeworrek J, West G, Stull R (2019) Evaluation of cumulus and microphysics parameterizations in WRF across the Convective Gray Zone. Weather Forecast 34:1097-1115. https://doi.org/10.1175/ waf-d-18-0178.1

Julia C, Rahn DA, Rutllant JA (2012) Assessing the influence of the MJO on strong precipitation events in subtropical, SemiArid North-Central Chile (30 degrees S). J Clim 25:7003-7013. https://doi.org/10.1175/jcli-d-11-00679.1

Kain JS (2004) The Kain-Fritsch convective parameterization: an update. J Appl Meteorol 43:170-181. https://doi.org/10.1175/ 1520-0450(2004)043\%3c0170:Tkcpau\%3e2.0.Co;2

Kalnay E et al (1996) The NCEP/NCAR 40-year reanalysis project. Bull Am Meteorol Soc 77:437-471. https://doi.org/10.1175/ 1520-0477(1996)077\%3c0437:tnyrp\%3e2.0.co;2

Kendon EJ et al (2017) Do convection-permitting regional climate models improve projections of future precipitation change? Bull Am Meteorol Soc 98:79-93. https://doi.org/10.1175/ bams-d-15-0004.1

Langenbrunner B, Pritchard MS, Kooperman GJ, Randerson JT (2019) Why does amazon precipitation decrease when tropical forests respond to increasing $\mathrm{CO}_{2}$ ? Earth Future 7:450-468. https://doi.org/10.1029/2018ef001026

Llopart M, Reboita MS, da Rocha RP (2020) Assessment of multimodel climate projections of water resources over South America CORDEX domain. Clim Dyn 54:99-116. https://doi.org/10. 1007/s00382-019-04990-z

Magrin G et al. (2014) Central and South America. In: Climate change 2014: impacts, adaptation, and vulnerability. Contribution of working group II to the fifth assessment report of the intergovernmental panel on climate change. Cambridge University Press, Cambridge and New York

Marengo JA, Soares WR, Saulo C, Nicolini M (2004) Climatology of the low-level jet east of the Andes as derived from the NCEPNCAR reanalyses: characteristics and temporal variability. J Clim 17:2261-2280. https://doi.org/10.1175/1520-0442(2004) 017\%3c2261:cotlje\%3e2.0.co;2

Masiokas MH, Villalba R, Luckman BH, Le Quesne C, Aravena JC (2006) Snowpack variations in the central Andes of Argentina and Chile, 1951-2005: Large-scale atmospheric influences and implications for water resources in the region. J Clim 19:63346352. https://doi.org/10.1175/jcli3969.1

Menne MJ, Durre I, Vose RS, Gleason BE, Houston TG (2012) An overview of the global historical climatology network-daily database. J Atmos Ocean Technol 29:897-910. https://doi.org/ 10.1175/jtech-d-11-00103.1 
Muller CJ, O'Gorman PA (2011) An Energetic perspective on the regional response of precipitation to climate change. Nat Clim Change 1:266-271. https://doi.org/10.1038/nclimate1169

Muñoz-Sabater J (2020) ERA5-land monthly averaged data from 1981 to present, Copernicus Climate Change Service (C3S) Climate Data Store (CDS). (Accessed October 12, 2020) https:// doi.org/10.24381/cds.68d2bb30

Myhre G et al (2018) Sensible heat has significantly affected the global hydrological cycle over the historical period Nature. Communications 9:1922. https://doi.org/10.1038/ s41467-018-04307-4

Pendergrass AG, Hartmann DL (2014) The atmospheric energy constraint on global-mean precipitation change. J Clim 27:757-768. https://doi.org/10.1175/jcli-d-13-00163.1

Posada-Marin JA, Rendon AM, Salazar JF, Mejia JF, Villegas JC (2019) WRF downscaling improves ERA-interim representation of precipitation around a tropical andean valley during El Nino: implications for GCM-Scale simulation of precipitation over complex terrain. Clim Dyn 52:3609-3629. https://doi.org/10.1007/ s00382-018-4403-0

Prein AF et al (2015) A review on regional convection-permitting climate modeling: demonstrations, prospects, and challenges. Rev Geophys 53:323-361. https://doi.org/10.1002/2014rg000475

Previdi M (2010) Radiative feedbacks on global precipitation. Environ Res Lett 5:11. https://doi.org/10.1088/1748-9326/5/2/025211

Richardson TB et al (2018a) Drivers of precipitation change: an energetic understanding. J Clim 31:9641-9657. https://doi.org/10. 1175/jcli-d-17-0240.1

Richardson TB et al (2018b) Carbon dioxide physiological forcing dominates projected eastern Amazonian drying. Geophys Res Lett 45:2815-2825. https://doi.org/10.1002/2017gl076520

Rummukainen M (2010) State-of-the-art with regional climate models. Wiley Interdiscip Rev Clim Change 1:82-96. https://doi.org/10. $1002 /$ wcc. 8

Schneider U, Becker A, Finger P, Meyer-Christoffer A, Ziese M (2018) GPCC full data monthly product version 2018 at $0.25^{\circ}$ : monthly land-surface precipitation from rain-gauges built on GTS-based and historical data. https://doi.org/10.5676/DWD_GPCC/FD_M_ V2018 025

Segura $\mathrm{H}$ et al (2019) New insights into the rainfall variability in the tropical andes on seasonal and interannual time scales. Clim Dyn 53:405-426. https://doi.org/10.1007/s00382-018-4590-8
Skamarock WC, Klemp JB (2008) A time-split nonhydrostatic atmospheric model for weather research and forecasting applications. J Comput Phys 227:3465-3485. https://doi.org/10.1016/j.jcp.2007. 01.037

Skinner CB, Poulsen CJ, Chadwick R, Diffenbaugh NS, Fiorella RP (2017) The role of plant $\mathrm{CO}_{2}$ physiological forcing in shaping future daily-scale precipitation. J Clim 30:2319-2340. https://doi. org/10.1175/jcli-d-16-0603.1

Solman SA (2013) Regional climate modeling over South America: a review. Adv Meteorol. https://doi.org/10.1155/2013/504357

Solman SA, Blazquez J (2019) Multiscale precipitation variability over South America: analysis of the added value of CORDEX RCM simulations. Clim Dyn 53:1547-1565. https://doi.org/10.1007/ s00382-019-04689-1

Taylor KE, Stouffer RJ, Meehl GA (2011) An overview of CMIP5 and the experiment design. Bull Am Meteorol Soc 93:485-498. https://doi.org/10.1175/BAMS-D-11-00094.1

Tencer B, Bettolli ML, Rusticucci M (2016) Compound temperature and precipitation extreme events in southern South America: associated atmospheric circulation, and simulations by a multi-RCM ensemble. Clim Res 68:183-199. https://doi.org/10.3354/cr01396

van Vuuren DP et al (2011) The representative concentration pathways: an overview. Clim Change 109:5-31. https://doi.org/10. 1007/s10584-011-0148-z

Vergara-Temprado J, Ban N, Panosetti D, Schlemmer L, Schar C (2020) Climate models permit convection at much coarser resolutions than previously considered. J Clim 33:1915-1933. https://doi.org/ 10.1175/jcli-d-19-0286.1

Viale M et al (2019) Contrasting climates at both sides of the Andes in Argentina and Chile. Front Environ Sci 7:15. https://doi.org/10. 3389/fenvs.2019.00069

Vuille M et al (2018) Rapid decline of snow and ice in the tropical Andes-impacts, uncertainties and challenges ahead. Earth Sci Rev 176:195-213. https://doi.org/10.1016/j.earscirev.2017.09.019

Publisher's Note Springer Nature remains neutral with regard to jurisdictional claims in published maps and institutional affiliations. 